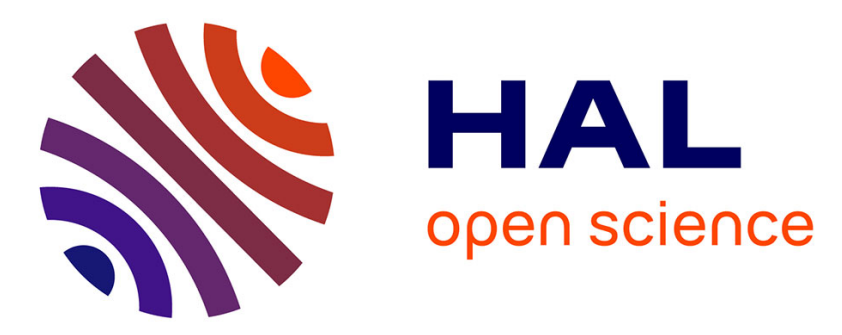

\title{
Alimentation du porc en croissance: intégration des concepts de protéine idéale, de disponibilité digestive des acides aminés et d'énergie nette
}

B. Sève

\section{- To cite this version:}

B. Sève. Alimentation du porc en croissance: intégration des concepts de protéine idéale, de disponibilité digestive des acides aminés et d'énergie nette. Productions Animales, 1994, 7 (4), pp.275-291. hal-00896092

\section{HAL Id: hal-00896092 \\ https://hal.science/hal-00896092}

Submitted on 1 Jan 1994

HAL is a multi-disciplinary open access archive for the deposit and dissemination of scientific research documents, whether they are published or not. The documents may come from teaching and research institutions in France or abroad, or from public or private research centers.
L'archive ouverte pluridisciplinaire HAL, est destinée au dépôt et à la diffusion de documents scientifiques de niveau recherche, publiés ou non, émanant des établissements d'enseignement et de recherche français ou étrangers, des laboratoires publics ou privés. 
INRA Prod. Anim.,

1994,7 (4), 275 - 291

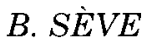

INRA Station de Recherches Porcines 35590 Saint-Gilles
Alimentation du porc en croissance : intégration des concepts de protéine idéale, de disponibilité digestive des acides aminés et d'énergie nette

\section{La satisfaction des besoins en acides aminés est une condition essentielle de l'expression du potentiel de croissance des porcs. Deux avancées récentes, la connaissance de la valeur énergétique nette des aliments et celle de la digestibilité iléale de leurs acides aminés, permettent de mieux caractériser la disponibilité des nutriments. Quels problèmes ces deux nouveautés résolvent-elles ou posent-elle dans l'expression des besoins et leur couverture ? Par ailleurs, le concept de protéine idéale a-t-il une signification pratique? Cet article tente de répondre à ces questions.}

Selon le principe de l'équilibre entre les protéines et l'énergie, il suffit que chacun des acides aminés essentiels soit fourni en quantité supérieure ou égale à un minimum par unité d'énergie pour assurer la vitesse de

\section{Résumé}

La valeur énergétique nette d'un aliment est déductible de sa teneur en énergie digestible selon une équation valable pour le porc à tous les stades physiologiques. Elle modifie la hiérarchie des matières premières en abaissant celles riches en protéines ou en fibres et en relevant celles riches en amidon ou en matières grasses. La protéine idéale théorique, de valeur biologique 1, est l'équivalent de l'énergie nette pour la couverture du besoin azoté. L'approche expérimentale de cette protéine par la suppression des excès d'acides aminés, laisse espérer une importante marge de progrès du rendement d'utilisation de l'azote absorbé. Ce rendement mesure une disponibilité métabolique de l'acide aminé limitant peu dépendante des matières premières utilisées. Celles-ci doivent être caractérisées plutôt par la disponibilité digestive de leurs acides aminés mesurable par leur digestibilité iléale. L'additivité des apports par différents constituants du régime nécessite une correction de leur digestibilité apparente pour les pertes endogènes non spécifiques de chacun d'entre eux, et la digestibilité "vraie" ainsi calculée peut être prédite à partir de leurs teneurs en subtances spécifiques. Toutefois, la présence dans l'indigestible "vrai" d'une fraction endogène spécifique pose le problème de sa quantification et de son coût de synthèse. L'apport minimum d'acide aminé limitant digestible (lysine) par unité d'énergie nette est toujours indépendant du niveau d'ingestion d'énergie chez le porc de moins de $55 \mathrm{~kg}$, alors qu'il est plus faible, et augmente avec le niveau de rationnement, chez le mâle castré plus lourd. Les apports minima des autres acides aminés sont déduits de rapports optimaux à la lysine déterminés expérimentalement. Certains déséquilibres par excès relativement à l'équilibre idéal nécessitent une correction (tryptophane/acides aminés neutres) ou un plafonnement des apports (thréonine). Des mécanismes d'épargne d'acides aminés essentiels (thréonine) par des non essentiels pourraient modifier leurs rapports optimaux à l'azote total. croissance maximum. Le taux de protéines de l'aliment résulte du calcul de la formule au moindre coût en fonction de la composition et du prix des matières premières disponibles sur le marché. L'ajustement est généralement effectué selon la théorie du facteur limitant. Une matière première "entre" dans la formule si elle permet de compléter la couverture du besoin en acide aminé limitant, souvent la lysine, à un coût plus faible qu'une ou plusieurs autres sources de protéines dont les apports sont alors réduits ou supprimés. En complément de ce système, l'énergie nette caractérise encore mieux que l'énergie digestible la valeur énergétique de l'aliment, tout en corrigeant la hiérarchie des matières premières. De la même façon, l'expression des apports d'acides aminés en quantités digérées avant l'extrémité de l'intestin grêle ("digestibilité iléale"), permet d'approcher leur disponibilité digestive. On devrait donc exprimer les besoins en acides aminés digestibles par unité d'énergie nette. Le concept de protéine idéale permet d'abord de repenser ce qu'on entend par disponibilité métabolique. Il permet également de moduler l'application stricte de la théorie du facteur limitant en prenant en compte les problèmes posés par les excès d'acides aminés et certaines relations d'équilibre privilégiées entre les acides aminés essentiels. Dans cette synthèse, nous tentons de présenter de manière critique l'application des anciens et des nouveaux concepts pour la formulation des aliments et les recommanda- 
Tableau 1. Equations de calcul de l'énergie nette (EN) des aliments pour les porcs (Noblet et al 1994).

$\mathrm{EN}_{1}=2,72 \mathrm{MAD}+8,37 \mathrm{MGD}+3,44$ Amidon $+2,89$ ResD

$\mathrm{EN}_{2}=0,703 \mathrm{ED}-0,98 \mathrm{MAT}+1,58 \mathrm{MG}-0,98 \mathrm{CB}+0,48$ Amidon

MAT = Matières azotées totales, MAD = Matières azotées digestibles, MG = Matières grasses,

MGD = Matières grasses digestibles, $\mathrm{CB}=$ Cellulose brute Weende, $\mathrm{CBD}=$ Cellulose brute digestible, ResD = Résidu

(Matière sèche - somme (matières minérales + matières azotées + sucres totaux + cellulose brute) digestible.

Tableau 2. Influence du système énergétique adopté sur la valeur énergétique des matières premières (base $100=$ blé) (Noblet et al 1989).

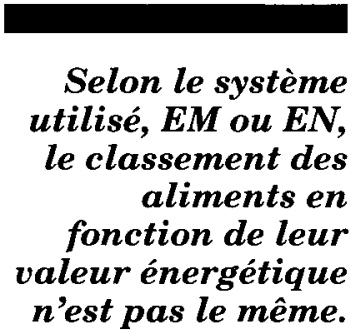

\begin{tabular}{|lccc|}
\hline Matière première & ED & EM & EN \\
\hline Blé & 100 & 100 & 100 \\
Orge & 93 & 93 & 95 \\
Maïs & 98 & 97 & 102 \\
Manioc & 98 & 99 & 106 \\
Tourteau de soja & 101 & 97 & 66 \\
Tourteau de tournesol & 58 & 52 & 41 \\
Tourteau de colza & 81 & 75 & 56 \\
Pois & 100 & 99 & 91 \\
Corn gluten feed & 54 & 49 & 53 \\
Mélasse de canne & 70 & 62 & 53 \\
Graisses animales & 184 & 187 & 240 \\
\hline
\end{tabular}

tions que l'on peut faire sur ces bases pour la couverture des besoins en acides aminés chez le porc en croissance et en finition.

\section{1 / Energie nette}

\section{1 / Concept d'énergie nette}

La valeur énergétique d'un aliment mesure son aptitude à satisfaire les besoins énergétiques d'entretien (énergie dissipée à croissance nulle), de croissance (gain de poids maigre ou gras) et/ou de production (porcelet, lait pour la truie). D'une façon générale, on l'exprime en énergie utilisable après soustraction des pertes mesurées aux différents niveaux de son assimilation par l'animal. L'expression du besoin en énergie digestible ne tient compte que des pertes d'énergie fécale, qui représentent effectivement le plus important facteur de variation de la valeur énergétique, en liaison notamment avec le taux de fibres ou, plus généralement, de parois cellulaires végétales. L'évaluation des pertes urinaires ou gazeuses (méthane), permet de calculer l'énergie métabolisable, déjà plus représentative de la valeur énergétique. Enfin, l'évaluation des pertes thermiques (extra-chaleur) associées à l'utilisation complète de l'aliment pour la satisfaction des besoins, conduit au calcul de l'énergie nette $(\mathrm{EN})$.

Le rendement de transformation de l'énergie métabolisable (EM) en EN varie d'abord en fonction de la nature des nutriments. Ainsi, le rendement d'utilisation de l'énergie des protéines digestibles $(0,47)$ est très inférieur à celui de l'amidon $(0,85)$ ou des lipides $(0,95)$, que les acides aminés soient fixés ou oxydés (Noblet et al 1989). L'énergie nette de croissan- ce $(\mathrm{ENc})$ correspond au gain énergétique corporel alors que l'énergie nette d'entretien (ENe) couvre la perte de chaleur de l'animal à jeun, le rendement d'utilisation de l'EM étant légèrement plus élevé pour l'entretien que pour la croissance. Comme, par ailleurs, le rendement pour le dépôt de lipides $(0,80)$ est supérieur au rendement pour le dépôt de protéines $(0,60)$, le contenu énergétique net de l'aliment devrait augmenter avec le poids vif. En réalité, cette variation est trop faible pour être mise en évidence expérimentalement (Noblet et al 1994), et l'animal plus lourd ou adulte (truie en gestation ou verrat) se distingue surtout par une capacité accrue de digestion de l'ensemble de la ration (Noblet et al 1993).

\section{2 / Equations de calcul de l'énergie nette}

Un important travail a permis d'établir des équations de calcul de l'énergie nette valables pour le porc en croissance. En première approximation, les mêmes équations de prédiction de l'énergie nette à partir des éléments digestibles peuvent être utilisées chez l'animal plus lourd ou adulte (Noblet et al 1994). Le tableau 1 indique par exemple les équations utilisables lorsqu'on dispose des tables INRA (1989) (Noblet et al 1989, 1994). Celles-ci donnent en général l'analyse dite fourragère, c'està-dire les teneurs en matières azotées totales (MAT), cendres, matières grasses et cellulose brute, ainsi que le fractionnement des constituants pariétaux de Van Soest (NDF et ADF), les matières grasses, l'amidon et l'énergie digestible. La deuxième équation $\left(\mathrm{EN}_{2}\right)$ montre clairement les différences d'évaluation entraînées par la substitution du système énergie nette au système énergie digestible. Une teneur élevée en MAT réduit la valeur 
Tableau 3. Profil de la protéine idéale pour croissance et entretien selon diverses estimations (base $100=1 y$ sine).

\begin{tabular}{|lccccc|}
\hline Profils & $\begin{array}{c}\text { Protéines } \\
\text { corporelles }^{(1)}\end{array}$ & $\begin{array}{c}\text { ARC } \\
(\mathbf{1 9 8 1})\end{array}$ & $\begin{array}{c}\text { INRA } \\
\mathbf{( 1 9 8 4 )}\end{array}$ & $\begin{array}{c}\text { Wang et } \\
\text { Fuller } \\
(\mathbf{1 9 8 9 )}\end{array}$ & $\begin{array}{c}\text { Chung et } \\
\text { Baker } \\
\mathbf{( 1 9 9 3 )}\end{array}$ \\
\hline Lysine g/16 g N & 7,0 & 7,0 & & 6,5 & \\
Lysine & 100 & 100 & 100 & 100 & 100 \\
Méthionine & 26 & - & - & - & 30 \\
Met + Cys & 49 & 50 & 60 & 63 & 60 \\
Thréonine & 57 & 60 & 60 & 72 & 18 \\
Tryptophane & 14 & 15 & 18 & 18 & 60 \\
Isoleucine & 50 & 55 & 60 & 60 & 100 \\
Leucine & 100 & 100 & 72 & 110 & 68 \\
Valine & 67 & 70 & 70 & 75 & 50 \\
Phénylalanine & 63 & - & - & - & 32 \\
Phe + Tyr & 96 & 96 & 96 & 120 & 42 \\
Histidine & 33 & 33 & 26 & - & \\
Arginine & 96 & - & 45 & - & \\
\hline
\end{tabular}

${ }^{(1)}$ Composition des protéines corporelles (moyennes de données bibliographiques).

énergétique nette (coefficient négatif), alors que des teneurs élevées en amidon ou en matières grasses l'augmentent (coefficients positifs). En revalorisant l'amidon, le calcul de l'énergie nette donne une prime aux céréales et au pois, c'est-à-dire aux principales matières premières métropolitaines. La teneur en parois végétales est déjà le principal facteur de diminution de la valeur ED d'un aliment. Le calcul de l'énergie nette entraîne une pénalisation supplémentaire des matières premières riches en cellulose (coefficient négatif). Au tableau 2, on constate par exemple que la valeur énergétique nette du tourteau de soja n'est que $66 \%$ de celle du blé, en raison de sa forte teneur en protéines, alors que les teneurs en énergie digestible des deux matières premières sont identiques. Au contraire, la valeur énergétique nette des graisses animales est 2,40 fois celle du blé, alors que la valeur ED n'est que de 1,84 fois celle du blé.

\section{3 / Besoin en énergie nette}

Le besoin énergétique, c'est d'abord le besoin d'entretien. L'établissement d'une proportionnalité de la production de chaleur au poids ( $\mathrm{P}$ ) élevé à la puissance 0,60 au lieu de 0,75 (Noblet et al 1989) a eu pour conséquence de relever sensiblement la part estimée de ENe dans EN chez les porcs en phase de croissance active ( 20 à $50 \mathrm{~kg}$ ). Le besoin énergétique de croissance est satisfait grâce à l'appétit de l'animal, le problème étant soit de favoriser cet appétit pour exprimer plus complètement le potentiel de croissance musculaire $d u$ porc, soit de restreindre l'ingéré pour éviter un engraissement excessif. On constate que l'appétit des porcs reste relativement constant en multiple du besoin d'entretien exprimé par $\mathrm{P}^{0,60}$, au lieu de diminuer entre 20 et $100 \mathrm{~kg}$ de poids vif. Avec cette référence pour la mesure de l'appétit, l'idée que l'ingestion d'énergie peut limiter les performances du porc dans la première phase de la croissance devient crédible (voir ci-dessous).

\section{2 / Protéine idéale et disponibilité des acides aminés}

Par définition, la valeur biologique (VB) mesure la proportion de l'azote absorbé utilisée pour la compensation des pertes endogènes (urinaires ou digestives) et le dépôt corporel (Mitchell 1924). Cet auteur avait proposé de mesurer la VB dans des conditions d'apport azoté limitant (régime à $10 \%$ de protéines chez le Rat). Toute protéine comporte un acide aminé limitant et un critère VB "acide aminé", analogue bien que non superposable à la VB "azote", peut être calculé pour l'acide aminé limitant. On peut faire un parallèle entre l'énergie et l'acide aminé limitant (lysine) aux différents niveaux de leur utilisation (figure 1). A l'énergie métabolisable correspond la lysine réellement absorbée. A l'énergie nette correspond la somme de l'azote ou de la lysine perdu à apport azoté nul et de l'azote ou de la lysine fixé dans les tissus. En d'autres termes, la VB et le rendement Kce de l'EM en EN ont exactement la même signification pour l'azote ou la lysine absorbé et l'EM respectivement.

\section{1 / Concept de protéine idéale}

La protéine idéale est définie comme celle dont tous les acides aminés seraient également limitants (Wang et Fuller 1989). Si sa VB "azote" pouvait atteindre la valeur théorique de 1,0 , la protéine idéale constituerait l'équivalent protéique de l'énergie nette. Les acides aminés fixés dans le gain de poids représentent le besoin net d'acides aminés pour la croissance ( $\mathrm{Nc}$ ), et il s'y ajoute le besoin net d'entretien (Nne), mesurable aussi bien par les pertes endogènes, digestive et urinaire, constatées avec un régime protéiprive, que par l'apport nécessaire à l'obtention du bilan azoté nul. En effet, à ces très faibles niveaux alimentaires, le rendement d'utilisation est très proche de 1,0 selon Fuller et al (1989).
La proteine idéale est constituée d'acides aminés en quantités telles qu'elle satisfait le besoin net de chacun d'entre eux. 
Figure 1. Correspondances entre rendements d'utilisation de l'azote ou de la lysine digestible $(N)$ et rendements d'utilisation de l'énergie métabolisable (EM).
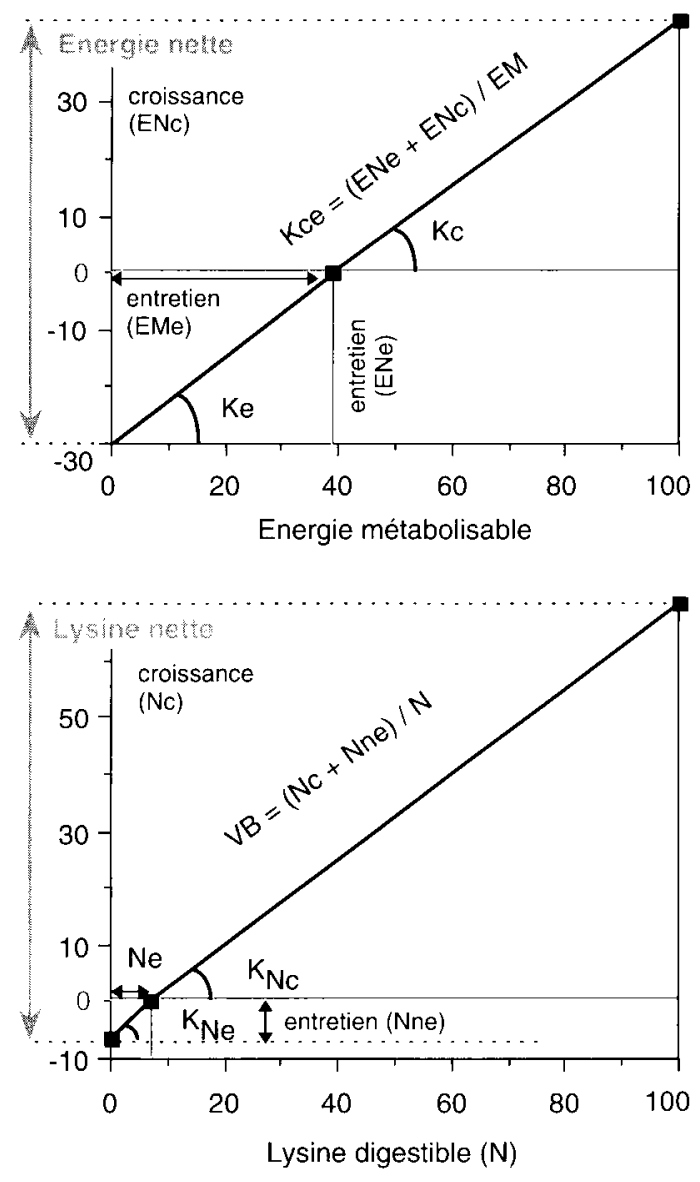

\section{$\mathbf{N}=\mathbf{N}$ digestible vrai total}

$\mathrm{Ne}=$ Besoin $\mathrm{N}$ pour entretien

$\mathrm{Nc}=\mathrm{N}$ fixé

Nne = Perte $\mathbf{N}$ endogène à apport nul
EM = énergie métabolisable

$\mathbf{E M e}=\mathbf{E M}$ entretien

$\mathrm{ENc}=$ Energie nette croissance

$\mathrm{ENe}=$ Energie nette entretien

= FHP (fasting heat production)

$\begin{array}{llll}\mathrm{N} \text { net } & =\mathrm{Nc}+\mathrm{Nne} & = & \mathrm{N} \text { de la protéine de } \mathrm{VB} 1,0 \text {, exemple de la lysine nette } \\ \mathrm{EN} & =\mathrm{ENc}+\mathrm{ENe} & = & \text { Energie nette } \\ \mathrm{CUN} & =\mathrm{Nc} / \mathrm{N} & & \text { utilisation nette de } \mathrm{N} \text { pour la croissance } \\ \mathrm{Kc} & =\mathrm{ENc} / \mathrm{EM} & = & \text { utilisation nette de } \mathrm{EM} \text { pour la croissance } \\ \mathrm{K}_{\mathrm{Ne}}=\mathrm{Nne} / \mathrm{Ne} \cong 1 & = & \text { rendement marginal de } \mathrm{N} \text { pour l'entretien } \\ \mathrm{Ke} & =\mathrm{ENe} / \mathrm{EMe} & = & \text { rendement marginal de EM pour l'entretien } \\ \left.\mathrm{K}_{\mathrm{Nc}}=\mathrm{Nc} / \mathrm{N} \cdot \mathrm{Ne}\right) & = & \text { rendement marginal de } \mathrm{N} \text { pour la croissance } \\ \mathrm{KG} & =\mathrm{ENc} / \mathrm{EM}-\mathrm{EMe}) & = & \text { rendement marginal de EM pour la croissance } \\ \mathrm{VB} & =(\mathrm{Nc}+\mathrm{Nne}) / \mathrm{N} & = & \text { valeur biologique } \\ \mathrm{K} & =(\mathrm{ENc}+\mathrm{ENe}) / \mathrm{EM} & = & \text { utilisation nette de } \mathrm{EM} \text { pour entretien et croissance }\end{array}$

d'excellente qualité, la vitesse de croissance maximum n'est souvent obtenue qu'au prix d'une diminution du rendement d'utilisation de l'azote pour le dépôt (Fuller et Garthwaite 1993). Une question importante est de savoir si cette diminution affecte tous les acides aminés de la même façon. En effet, dans le cas contraire, l'équilibre de la protéine idéale permettant de maximiser le gain de poids devrait s'écarter plus largement de celui de la protéine de VB 1,0 , ou de celui de la composition corporelle.

Une approche expérimentale plus analytique de la protéine idéale, chez des porcs de $40 \mathrm{~kg}$, a permis de montrer que sa composition est extrêmement différente pour l'entretien et la croissance (Fuller et al 1989, tableau 4). On remarque notamment que les besoins relatifs en acides aminés soufrés et en thréonine, exprimés en pourcentage de la lysine, sont nettement plus élevés pour l'entretien que pour la croissance, bien que ceci ait peu d'influence sur le profil combiné pour la couverture simultanée des deux besoins. Mais on remarque aussi que le profil optimal pour la croissance seule, également exprimé en pourcentage de la lysine, diffère sensiblement de celui des protéines corporelles. Ceci correspond à de notables différences de rendement marginal $\left(\mathrm{K}_{\mathrm{Nc}}\right)$ d'utilisation pour le dépôt entre acides aminés. La lysine présenterait le $\mathrm{K}_{\mathrm{Nc}}$ le plus élevé (proche de 1,0 , d'après Fuller et al 1989), précédant les acides aminés soufrés (méthionine plus cystine), alors que les rendements d'utilisation de la thréonine et du tryptophane seraient relativement bas. Ce résultat s'explique par les métabolismes et les rôles physiologiques particuliers des acides aminés essentiels et implique que les rapports optima à la lysine subissent une dérive supplémentaire, en plus de celle provoquée par la prise en compte du besoin d'entretien, lorsque le porc exprime son potentiel de croissance.

La protéine idéale n'est pas complètement définie par le profil des acides aminés essentiels, il reste à fixer le rapport optimal entre ces acides aminés et l'azote total, autrement dit à exprimer le besoin de chaque acide aminé en $\mathrm{g}$ pour $16 \mathrm{~g}$ d'azote (équivalent à $100 \mathrm{~g}$ de protéines brutes). Selon Wang et Fuller (1989), les acides aminés indispensables doivent fournir une fraction de l'azote total comprise entre 0,45 et 0,50 (tableau 5 ), chiffre confirmé par Chung et Baker (1991). Toutefois, à notre avis, les protocoles d'étude utilisés par ces deux équipes présentent le défaut de ne pas s'assurer que l'apport total d'azote par unité d'énergie du régime, permet d'obtenir la vitesse de croissance maximum. Wang et Fuller (1989) rapportent pour leur protéine idéale une VB "azote" de 0,93, alors que la VB calculée pour la lysine, l'acide aminé essentiel le plus efficacement utilisé, n'est que de 0,82. La comparaison de ces deux VB suggère que celle de l'azote non essentiel est supérieure à $1,0 \mathrm{du}$ fait de l'utilisation d'acides aminés essentiels comme précurseurs des non essentiels. Si les auteurs avaient accru l'apport d'acides aminés non essentiels, en conservant constant l'apport d'acides aminés essentiels, ces derniers 
Tableau 4. Apports idéaux d'acides aminés pour l'entretien et la croissance chez le Porc et rendements marginaux correspondants d'utilisation des acides aminés (d'après Fuller et al 1989).

\begin{tabular}{|lcc|cc|cc|}
\hline Besoin & Croissance & Entretien & Croissance & Entretien & Croissance & Entretien \\
\hline & $\begin{array}{c}\mathbf{m g} / \mathbf{g} \\
\text { protéines } \\
\text { fixées }\end{array}$ & $\begin{array}{c}\mathbf{m g} / \mathbf{k g} \\
\mathbf{P 0}, \mathbf{7 5}\end{array}$ & $\begin{array}{c}\text { \% de } \\
\text { lysine }\end{array}$ & $\begin{array}{c}\text { \% de } \\
\text { lysine }\end{array}$ & $\begin{array}{c}\text { Rendements } \\
\mathbf{K} \mathbf{N c}\end{array}$ & $\mathbf{K}_{\mathbf{N e}} \mathbf{( 1 )}$ \\
\hline Azote & - & 244 & - & & & 1,0 \\
Lysine & 68 & 36 & 100 & 100 & 1,03 & 1,88 \\
Méthionine & 19 & 9 & 28 & 25 & 0,98 & 2,64 \\
Met + Cys & 36 & 49 & 53 & 139 & 0,97 & 1,55 \\
Thréonine & 47 & 53 & 69 & 147 & 0,85 & 1,44 \\
Tryptophane & 12 & 11 & 18 & 31 & 0,83 & 0,94 \\
Isoleucine & 43 & 16 & 63 & 44 & 0,82 & 1,71 \\
Leucine & 78 & 23 & 115 & 64 & 0,90 & 3,20 \\
Valine & 53 & 20 & 77 & 55 & 0,89 & 1,85 \\
Phénylalanine & 41 & 18 & 60 & 50 & 0,97 & 2,10 \\
Phe + Tyr & 84 & 37 & 124 & 103 & 0,80 & 1,68 \\
\hline
\end{tabular}

${ }^{11} \mathrm{C}$ rendement supérieur à 1 est dû à l'exagération de la perte azotée $\left(\mathrm{K}_{\mathrm{Ne}} \mathrm{x} \mathrm{Ne}\right.$ pour $\left.\mathrm{N}=0\right)$ lorsqu'un acide aminé est limitant avec un large excès des autres. Pour le calcul des VB "acides aminés" on a utilisé la perte d'acide aminé calculée avec $\mathrm{K}_{\mathrm{Ne}}=1,0$, comme pour l'azote.

Tableau 5. Ajustement des apports d'azote d'acides aminés non essentiels à celui des essentiels équilibré selon la protéine idéale (Wang et Fuller 1989, sauf dernière ligne: ARC 1981).

\begin{tabular}{|lccc|}
\hline N essentiel : & $\begin{array}{c}\text { Lysine } \\
\text { N non essentiel }\end{array}$ & $\begin{array}{c}\text { Rétention N } \\
\mathbf{g}^{\prime} \mathbf{k g}^{\mathbf{0}, 75}\end{array}$ & VB \\
\hline $36: 64$ & 5 & 0,88 & 0,84 \\
$43: 57$ & 6 & 0,96 & 0,90 \\
$50: 50$ & 7 & 1,00 & 0,93 \\
$57: 43$ & 8 & 0,99 & 0,92 \\
$45: 55$ & 7 & 0,95 & 0,89 \\
\hline
\end{tabular}

auraient pu être utilisés plus efficacement et les performances des porcs auraient pu augmenter. En appliquant un tel protocole chez le Rat, Heger et al (1987) obtiennent un rapport optimal N essentiel : $N$ total de 0,40 seulement.

Les données de Fuller et al (1989) suggèrent que la valeur biologique 1,0 peut être réalisée en pratique au moins pour la lysine, le coefficient d'utilisation nette pour la croissance étant de 0,93. En fait, le CUN de la lysine obtenu réellement dans l'expérience rapportée par ces auteurs, dans laquelle le régime témoin renfermait la protéine idéale précédemment déterminée pour la croissance et l'entretien (Wang et Fuller 1989), n'était que de 0,78. Le CUN de la lysine de cette même protéine testée par Chung et Baker (1992a) chez des porcelets de $10 \mathrm{~kg}$ peut être estimé à 0,67 . La méthode utilisée par Fuller et al (1989) surestime-t-elle le rendement d'utilisation des acides aminés? La question reste posée.

\section{2 / Distinction entre disponibilité digestive et disponibilité métabolique des acides aminés}

Selon la définition de Mauron reprise par Rérat (1971), la disponibilité d'un acide aminé, c'est la proportion de cet acide aminé utilisée pour la synthèse protéique lorsqu'il constitue le facteur limitant du régime. Batterham (1992) rappelle que ce critère intègre deux composantes, l'une digestive, l'autre métabolique. La première composante est quantifiable par une mesure de digestibilité vraie (voir cidessous la définition du CUDv). La seconde est quantifiable par une mesure de VB "acide aminé" telle que nous l'avons définie ci-dessus. Pour évaluer simultanément ces deux composantes de la valeur nutritionnelle d'une protéine, on peut éventuellement pratiquer des tests de réponse globale à l'apport de différentes doses de l'acide aminé limitant par cette protéine, en mesurant le gain de poids, le gain de muscle ou de carcasse (Batterham 1992) ou le bilan corporel d'azote. Outre le peu de précision de leurs résultats, ces tests risquent de fournir des valeurs de disponibilité très dépendantes des conditions expérimentales. En effet, le rendement d'utilisation métabolique de l'azote varie souvent moins selon les caractéristiques propres à la matière première étudiée qu'en fonction de paramètres liés à l'animal et au mode d'alimentation ou de supplémentation pratiqué. L'effet du besoin protéique par unité d'énergie, dépendant du poids du porc, est évoqué plus loin (voir 3.1) Selon certains auteurs, l'alimentation en un seul repas diminuerait l'efficacité métabolique de la lysine libre comparativement à la lysine liée aux protéines (Batterham 1984, Batterham et Bayley 1989), voire à des oligopeptides (Rérat et al 1992), un inconvénient probablement très atténué en alimentation libérale (Bourdon et Henry 1985).

Au plan métabolique, deux autres facteurs, plus spécifiques de la protéine étudiée, peuvent modifier la disponibilité de l'acide aminé.

D'abord, celui-ci peut être apporté sous forme modifiée, détectable à l'analyse, parfois digestible mais non utilisable pour la synthèse protéique (Batterham 1992). Le cas le plus connu est celui de la lysine dont le groupe $\varepsilon$ -
La composition en acides aminés de la protéine idéale n'est pas la même pour l'entretien et pour la croissance. 
Figure 2. Réponse du gain de poids à la supplémentation en tryptophane d'un régime basal carencé avec du tourteau de soja, ou avec du L-tryptophane libre en présence ou non de l'excès des acides aminés apportés simultanément parle tourteau de soja (Sato et al 1986).

Gain de poids $(\mathrm{g} / \mathrm{j})$

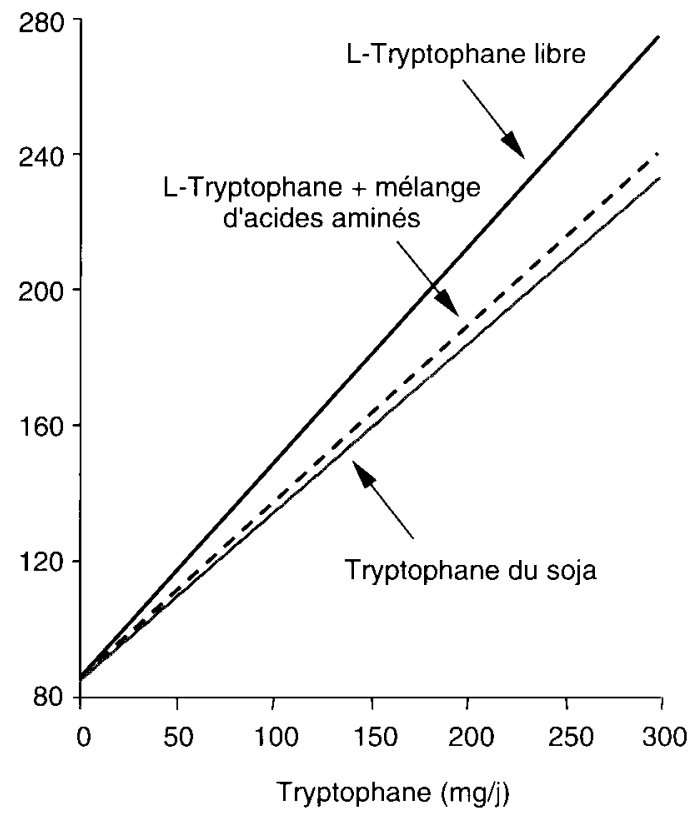

$\mathrm{NH}_{2}$ peut être "bloqué" par un traitement chimique ou thermique provoquant la formation d'isopeptides ou d'hétérosides (Carpenter et Booth 1973). La lysine non "bloquée", et donc disponible si elle est absorbée, peut être dosée par réaction au fluorodinitrobenzène (Carpenter 1960, Roach et al 1967) ou par guanidination en homoarginine (Erbersdobler et Lee 1991). Toutefois, lorsque la lysine dite "bloquée" est digérée et absorbée, il est difficile d'évaluer sa disponibilité métabolique (Van Barneveld 1993).

Par ailleurs, la disponibilité semble être influencée aussi par les excès relatifs d'autres acides aminés que le limitant dans le régime (voir Rérat 1971, pour les données classiques en la matière). Plus récemment, chez le porc, Sato et al (1987) montrent que la réponse de la croissance à l'addition de tryptophane est infléchie par l'addition au régime basal des acides aminés apportés en excès par la protéine testée (figure 2). La disponibilité corrigée pour l'existence de cet excès ne s'appliquera pas forcément à une protéine d'équilibre différent en acides aminés. Noblet et al (1987) montrent que les acides aminés en excès stimulent le dépôt de protéines dans les viscères, et non dans les muscles, participant ainsi à l'hypertrophie d'un compartiment corporel à turnover très rapide (Sève et al 1986). Ainsi pourrait s'expliquer la relative inefficacité du facteur limitant apporté concomitamment. Les acides aminés en excès semblent influencer différemment la disponibilité métabolique du facteur limitant lorsque l'apport est inférieur au besoin d'entretien. Ainsi, dans l'une des expériences de Fuller et al (1989), l'excès des acides aminés non limitants s'accompagne de valeurs $\mathrm{du}$ rendement pour l'entretien $\left(\mathrm{K}_{\mathrm{Ne}}\right)$ supérieures à 1 (cf tableau 5). Autrement dit, le déséquilibre entraîne une forte stimulation des pertes endogènes et tout accroissement de l'apport d'acide aminé limitant agit autant en réduisant ces pertes qu'en les compensant. A ce très faible niveau d'apport du facteur limitant, l'excès des autres acides aminés provoquerait donc soit une accélération du turnover des protéines, soit un accroissement des secrétions digestives non récupérées.

En définitive, on ne peut prétendre caractériser les matières premières par un critère global disponibilité des acides aminés, il semble préférable d'évaluer la disponibilité digestive, puis de prendre en compte les facteurs affectant la disponibilité métabolique. En ce qui concerne les effets des traitements thermiques, des méthodes de correction pour les acides aminés digestibles indisponibles restent à élaborer. Conformément au concept de protéine idéale, les déséquilibres par excès peuvent faire l'objet de contraintes spécifiques de formulation.

\section{3 / Digestibilité iléale apparente, vraie ou réelle des acides aminés}

Le bilan digestif effectué au niveau fécal, acceptable pour l'évaluation énergétique, biaise profondément l'estimation de la quantité d'acide aminé réellement absorbée. Les acides aminés des fèces ne correspondent pas forcément aux acides aminés alimentaires échappant à l'absorption. Ils peuvent avoir été dégradés par la flore microbienne et celle-ci peut même avoir resynthétisé de novo certains d'entre eux. Le site majeur de l'activité microbienne digestive est le gros intestin. C'est pourquoi, un bilan digestif approchant de manière satisfaisante la disponibilité des acides aminés peut être obtenu au niveau iléal, juste avant l'entrée des résidus non digérés dans le côlon. De nombreuses techniques ont été proposées pour effectuer ces mesures, mettant en jeu soit la pose de canules de divers types, soit l'anastomose iléo-rectale, c'est à dire un "shunt" de l'ensemble du gros intestin (Picard et al 1984). En France, la variante dite termino-terminale de cette dernière technique, évitant les contaminations bactériennes au moyen d'une isolation complète du côlon, est la plus généralement utilisée (Laplace et al 1985, 1989; Green et al 1987). Toutefois, les matières premières ne sont effectivement bien caractérisées, et les apports d'acides aminés digestibles ne peuvent être additifs (Furuya et Kaji 1991), que si l'on retranche de l'indigestible total la fraction d'origine endogène, non spécifique de la matière première, proportionnelle à la matière sèche ingérée, ou au poids métabolique de l'animal lorsque la quantité d'aliment ingérée est trop faible (MariscalLandin et al 1994). Cette correction de la digestibilité apparente

CUDa $=100$ (ingéré - excrété)/ingéré (1) conduit au calcul de la digestibilité vraie ou standardisée

(CUDv = 100 [ingéré - (excrété - endogène)]/ingéré (2) 
Tableau 6. Biais introduit par l'utilisation des valeurs de digestibilité apparente dans le calcul des acides aminés disponibles d'un régime maïs-soja à $17 \%$ de protéines (données exprimées en \% de l'aliment en utilisant les valeurs de digestibilité proposées par Rhône-Poulenc Animal Nutrition 1989).

\begin{tabular}{|lccccc|}
\hline & $\begin{array}{c}\text { Digestible } \\
\text { apparent }\end{array}$ & $\begin{array}{c}\text { Digestible } \\
\text { vrai }\end{array}$ & endogène $^{(1)}$ & $\begin{array}{c}\text { apparent } \\
\text { non biaisé }\end{array}$ & $\begin{array}{c}\text { biais } \\
\%\end{array}$ \\
\hline Lysine & 0,671 & 0,733 & 0,033 & 0,700 & $-4,1$ \\
Méthionine & 0,238 & 0,253 & 0,009 & 0,244 & $-2,5$ \\
Met + Cys & 0,456 & 0,500 & 0,027 & 0,473 & $-3,6$ \\
Thréonine & 0,478 & 0,548 & 0,045 & 0,503 & $-5,0$ \\
Tryptophane & 0,147 & 0,169 & 0,016 & 0,153 & $-3,9$ \\
Leucine & 1,384 & 1,453 & 0,044 & 1,409 & $-1,8$ \\
Isoleucine & 0,625 & 0,668 & 0,021 & 0,647 & $-3,4$ \\
Valine & 0,681 & 0,743 & 0,035 & 0,708 & $-3,8$ \\
Phénylalanine & 0,716 & 0,760 & 0,028 & 0,732 & $-1,2$ \\
Phe + Tyr & 1,256 & 1,340 & 0,051 & 1,284 & $-1,2$ \\
\hline
\end{tabular}

(1) endogène standard selon Wünsche et al 1987 (régime à $87 \%$ de matière sèche).

Elle est nécessaire car, alors que le CUDv est bien une donnée constante, le CUDa augmente avec le taux de protéines ou d'acide aminé du régime servant à le mesurer :

$$
\mathrm{CUDa}=\mathrm{CUDv}-\mathrm{AAEms} / \mathrm{AAms}(3)
$$

AAEms est l'excrétion endogène d'acide aminé/kg d'ingéré sec de régime protéiprive. Les valeurs moyennes de la bibliographie rapportées par Wünsche et al (1987) sont généralement adoptées. Nous avons confirmé leur validité en définissant notre propre méthodologie de mesure (Mariscal-Landin et al 1990). AAms est la concentration de l'acide aminé dans l'ingéré sec.

Ainsi, le CUDa des matière premières pauvres en protéines, notamment les céréales, sous-estime leur apport d'acides aminés disponibles comparativement à celui des sources de protéines complémentaires et pénalise injustement les régimes céréales-tourteaux (tableau 6). On remarque que la pénalisation affecte plus particulièrement les facteurs limitants des céréales, la lysine et surtout la thréonine.

Les calculs sont effectués en utilisant les tables de composition des matières premières en acides aminés digestibles dont un certain nombre ont été proposées (Rhône Poulenc Animal Nutrition 1989 et 1993, ITCFEurolysine 1993). Un obstacle à la mise en application efficace de l'outil "digestibilité iléale" tient à la grande variabilité des données intra-type de matières premières et au caractère aléatoire de l'application d'une valeur "table" unique. L'étude des facteurs de variation de la digestibilité est en cours (MariscalLandin 1992, Jondreville et al 1994). Dans l'ensemble, ces travaux montrent que la digestibilité peut être prédite à partir des teneurs en substances caractéristiques de chaque type de matière première. Si ces facteurs de variation étaient correctement identifiés, il devrait être possible de faire apparaitre la correction d'endogène non spécifique dans une équation de prédiction de la digestibilité apparente. Nous l'avons confirmé pour les issues de blé avec les acides aminés les plus représentés dans les pertes endogènes, par exemple la thréonine (Thr) (Sève et al 1994) :

$$
\begin{array}{ll}
\text { CUDaThr }=92,9( \pm 2,7) & -0,79( \pm 0,11) \times \text { ADFms/Thrms } \\
& -0,50( \pm 0,17) \times \text { N.NDF } \\
& -0,38( \pm 0,09) / \text { Thrms }(4)
\end{array}
$$

$\mathrm{R}^{2}=0,98 ; \mathrm{ETR}=1,4 ; \mathrm{n}=11$.

$\mathrm{ADFms}=\mathrm{g} A D F$ par $\mathrm{kg}$ de matière sèche du régime.

Thrms $=\mathrm{g}$ thréonine par $\mathrm{kg}$ de matière sèche du régime.

$\mathrm{N} . \mathrm{NDF}=$ azote associé au résidu NDF, \% de $\mathrm{N}$ total.

En identifiant l'équation (4) avec l'équation (3) ci-dessus, on déduit que le CUDv, exprimé ici en \%, peut-être estimé par une équation linéaire à deux variables, la teneur en ADF de Van Soest exprimée en g/g de thréonine et la proportion de l'azote de la matière première associée au résidu NDF de Van Soest, deux critères caractérisant bien la matière première indépendamment du régime utilisé pour la mesure. L'explication du CUDa intègre alors bien l'endogène non spécifique ThrEms que l'on peut estimer à environ 0,38 $\mathrm{g} / \mathrm{kg}$ d'ingéré sec, contre $0,51 \mathrm{~g} / \mathrm{kg}$ pour l'endogène standard moyen (Wünsche et al 1987). La nature des fibres étant susceptible d'influer directement sur la perte endogène, ce nouvel endogène, calculé à taux de constituants pariétaux nul, serait donc probablement plus adéquat pour la correction du CUDa que l'endogène standard habituel. Ce dernier correspond en effet à l'excrétion observée avec un régime protéiprive généralement enrichi en fibres pour simuler les régimes habituels du porc (Wünsche et al 1987, Mariscal-Landin et al 1990). Toutefois, le calcul du nouvel endogène n'est possible avec précision que lorsque le CUDv peut être prédit correctement. Ce n'est pas le cas pour la lysine des issues de blé, dont la digestibilité est insuffisamment expliquée par les constituants pariétaux ou l'azote qui leur est associé (Sève et al 1994). En attendant des estimations plus précises, l'endogène standard déterminé en présence de fibres purifiées, relativement neutres en termes de stimulation de l'excrétion endogène, reste une approximation acceptable de l'endogène non spécifique.

Des équations de détermination directe $d u$ CUDv mettant en jeu des prédicteurs spécifiques peuvent être appliquées à chaque type
La digestibilité iléale vraie des acides aminés tient compte de la perte endogène non spécifique de la source de protéines. 
Tableau 7. Exemples de prédiction de la digestibilité iléale vraie de la lysine en fonction des teneurs en constituants caractéristiques (en \% de la matière sèche sauf indication contraire) de divers types de sources de protéines (Mariscal-Landin 1992, Sève et al 1994).

\begin{tabular}{|c|c|c|c|c|c|}
\hline Issues de blé & $(\mathrm{n}=11)$ & CUDv Lys & $=97,5$ & - 1,19 ADF/Lys ${ }^{1 /}$ & $R^{2}=0,84$ \\
\hline Pois & $(\mathrm{n}=5)$ & CUDv Lys & $=90,6$ & - 1,31 facteur antitrypsique & $R^{2}=0,67$ \\
\hline Sorgho & $(n=4)$ & CUDv Lys & $=73.2$ & $-19,1$ tanins & $R^{2}=0,95$ \\
\hline Farines de viande & $(\mathrm{n}=5)$ & CUDv Lys & $=13,3$ & + 0,75 Lys Carpenter ${ }^{(2 \mid}$ & $\mathrm{R}^{2}=0,99$ \\
\hline Farines animales & $(\mathrm{n}=10)$ & CUDv Lys & $=40,7$ & + 0,45 Lys Carpenter & $R^{2}=0,49$ \\
\hline \multirow[t]{2}{*}{ Farines animales } & $(\mathrm{n}=10)$ & $\begin{array}{l}\text { CUDv Lys } \\
\text { CUDv Lys }\end{array}$ & $\begin{array}{l}=10,5 \\
=25,4\end{array}$ & $\begin{array}{l}+0,94 \mathrm{~N} \text { solubilisé in vitro } \\
+0,65 \mathrm{~N} \text { solubilisé in vitro }\end{array}$ & $\mathrm{R}^{2}=0,57$ \\
\hline & & & & + 0,25 Lys libérée in vitro & $\mathrm{R}^{2}=0,71$ \\
\hline
\end{tabular}

ADF/Lys = Résidu sec après action du détergent acide de Van Soest (\% de matière sèche), g/g de lysine.

"Lysine gardant son groupe epsilon-aminé libre (\% de lysine totale), dosée selon Roach et al (1967).

Elle peut être prédite à partir de caractéristiques physico-chimiques de chaque matière première. de matières premières (tableau 7). Ainsi, nous avons pu montrer que le CUDv de la lysine, comme celui de la thréonine, est inversement proportionnel à la teneur en ADF de Van Soest exprimée en g par g d'acide aminé. En revanche, la teneur en parois végétales du tourteau de tournesol n'influence absolument pas le CUDv des acides aminés de cette matière première. Dans le cas du pois, c'est le facteur antitrypsique qui explique le mieux les variations de digestibilité des acides aminés. Les tanins expliquent très bien celles du sorgho. La lysine "Carpenter" est un bon prédicteur pour les farines de viande, mais moins bon pour les autres farines animales (farines de sang et de poisson). Alternativement, ou complémentairement, à ces dosages de substances particulières, des mesures de digestibilité in vitro sont actuellement mises au point dans quelques laboratoires. Une telle tentative est présentée au tableau 7 dans le cas des farines d'origine animale. Les équations décrivant la variation du CUD en fonction de ces facteurs peuvent être utilisées, mais la précision n'est suffisante que lorsque deux ou plusieurs facteurs agissant indépendamment sont combinés dans des équations de régression multiple. Ces équations devraient permettre, à terme, de prédire le CUDv en se dispensant de mesures difficiles et coûteuses.

Il faut maintenant souligner que la digestibilité "vraie" n'est qu'une digestibilité apparente corrigée permettant, sinon de rendre parfaitement additives les quantités d'acides aminés digestibles provenant d'une combinaison de matières premières, du moins d'éliminer la cause majeure de non-additivité que représente la perte endogène non spécifique. Toutefois, Les pertes réelles totales d'endogène, dont on tient compte dans le calcul de la digestibilité réelle (CUDr), peuvent être mesurées par marquage à l'azote ${ }^{15} \mathrm{~N}$ de l'animal (de Lange et al 1990) ou de l'aliment. Le marquage de celui-ci peut également être fait à l'homoarginine (Hagemeister et Roos 1991), la guanidination de la lysine n'affectant pas son utilisation digestive. Par ailleurs, des méthodes statistiques ont été proposées pour effectuer la partition des protéines de digesta iléaux en leurs éléments constitutifs (Duvaux et al 1990). Les résultats montrent qu'une fraction non négligeable et variable de l'indigestible "vrai" peut être également d'origine endogène, l'indigestible réel, strictement d'origine alimentaire, étant parfois même insignifiant (Le Guen 1993). On peut parler alors d'une perte endogène spécifíque car stimulée par des constituants caractéristiques de chaque source de protéines, polyholosides non amylacés, alpha-galactosides, tanins ou facteurs antinutritionnels protéiques tels que les inhibiteurs trypsiques, les lectines ou les allergènes. Il faut se garder de voir là une raison de réhabiliter la digestibilité apparente non corrigée puisque la perte digestive endogène spécifique est mesurée par la différence CUDr - CUDv. Le problème du rendement des acides aminés alimentaires pour la couverture des besoins correspondants aux deux types de dépenses endogènes digestives est alors posé. La dépense endogène digestive non spécifique, relativement peu importante chez un animal en croissance, constitue une partie du besoin d'entretien au même titre que celle associée à la perte azotée urinaire obligatoire. Nous avons vu plus haut que le rendement d'utilisation $\mathrm{K}_{\mathrm{Ne}}$ applicable à ce besoin net pouvait être estimé à 1,0. La question est de savoir si, lorsqu'il devient quantitativement important, l'endogène digestif spécifique n'est pas produit avec un rendement marginal $\mathrm{K}_{\mathrm{Nc}}$ ' plus proche du rendement $K_{N}$ pour la croissance. $\mathrm{Si}$ c'était le cas, le meilleur critère de disponibilité digestive serait le CUDv corrigé de la perte d'acides aminés disponibles nécessaire à la synthèse nette d'endogène digestif spécifique. La perte totale associée à l'endogène spécifique étant (CUDr - CUDv)/KNc', on devrait écrire :

\section{CUDv corrigé $\left.=\mathrm{CUDv}-(\mathrm{CUDr}-\mathrm{CUDv})\left(1 / \mathrm{KNc}^{\prime}-1\right)\right)$}

Par exemple, si $\mathrm{K}_{\mathrm{Nc}}$ ' devait être estimé à 0,75 , dans le cas du pois Finale présentant des CUDa et CUDv de l'azote de 74 et $83 \%$ respectivement (Mariscal-Landin 1992) et un CUDr de 95 (Huisman et al 1992), le CUDv corrigé serait de 79. Dans le cas d'un son de blé présentant des CUDa, CUDv et CUDr de l'azote de 60,72 et 80 respectivement (d'après Mariscal-Landin 1992) le CUDv corrigé serait de 69. Il est donc impératif de clarifier cette situation par des études métaboliques plus approfondies. 
Figure 3. Relations entre le dépôt protéique et les apports journaliers de protéines et d'énergie chez le porc de $35 \mathrm{~kg}$ en croissance (d'après Campbell et al 1985). EN = énergie nette ingérée, $E N e=$ énergie nette d'entretien.

Protéines fixées $(\mathrm{g} / \mathrm{j})$
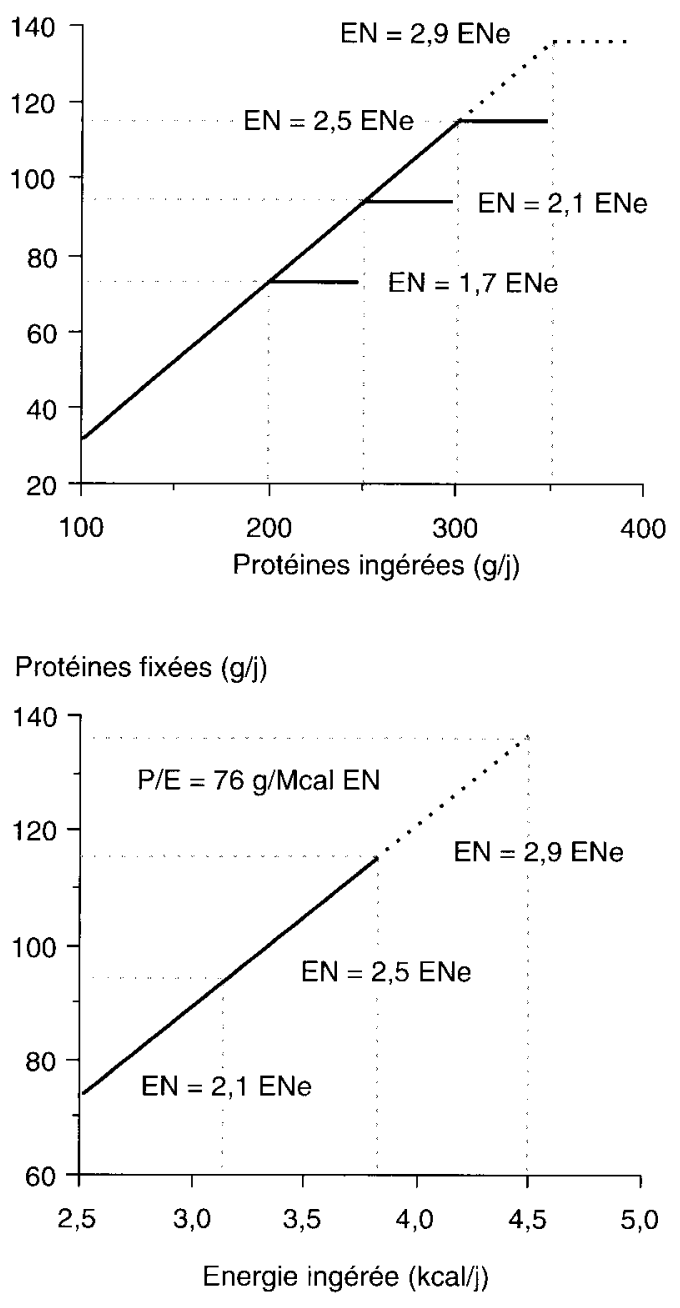

Figure 4. Relations entre le dépôt protéique et les apports journaliers de protéines et d'énergie chez le porc de $70 \mathrm{~kg}$ en finition (basé sur les données de Schneider et al 1982 et Campbell et al 1984). EN= énergie nette ingérée, $\mathrm{ENe}=$ énergie nette d'entretien. Protéines fixées $(g / j)$

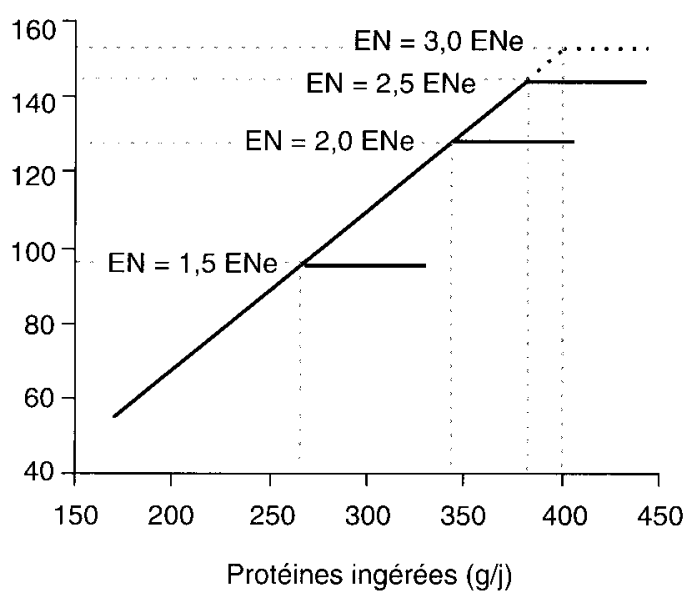

Protéines fixées $(\mathrm{g} / \mathrm{j})$

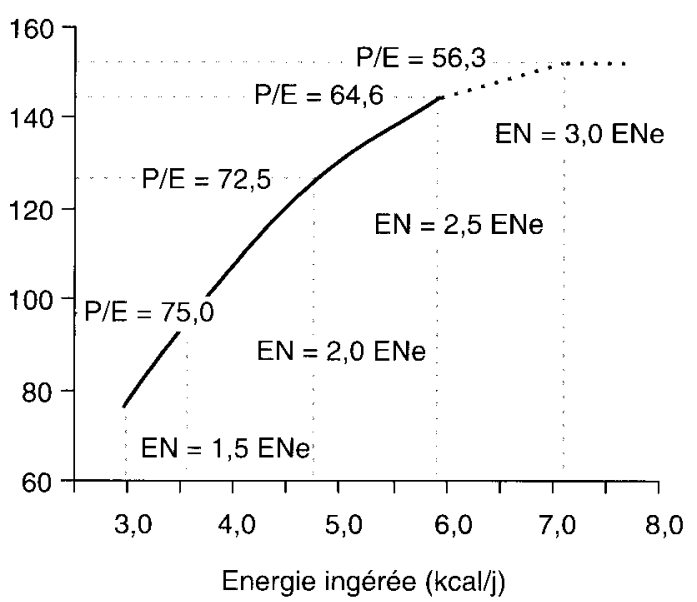

Le dépôt protéique augmente linéairement avec la quantité de protéines ingérées, jusqu'à un plateau déterminé par l'apport énergétique net.

\section{3 / Besoin en azote et en acides aminés par unité d'énergie nette}

\section{1 / Influence de l'énergie sur la rétention azotée}

Chez l'animal en phase de croissance active, (20-50 kg) les courbes, assimilables ou non à des droites, de réponse de la rétention azotée à l'apport de protéines équilibrées sont approximativement confondues, pour tous les apports énergétiques, jusqu'à un rapport optimum unique protéines équilibrées (ou acide aminé limitant) sur énergie (Campbell et al 1985a). A partir de cette valeur optimale protéines/énergie, la rétention azotée est en plateau, et le niveau de ce plateau augmente linéairement avec la quantité d'énergie ingérée jusqu'à un maximum déterminé par l'ingéré énergétique à volonté (figure 3). En phase de croissance, tout se passe donc comme si l'expression du poten- tiel de croissance n'était plus limitée que par l'appétit de l'animal, dès que l'apport d'acide aminé limitant dépasse le minimum recommandé par unité d'énergie.

A un stade de croissance plus avancé, entre 50 et $100 \mathrm{~kg}$ de poids vif, surtout chez les porcs mâles castrés de type génétique peu performant, le potentiel de dépôt azoté ou de croissance musculaire est atteint avec un niveau d'ingestion d'énergie inférieur à celui obtenu en alimentation à volonté (Campbell et al $1985 b$, Dunkin et al 1986). Le maintien de la linéarité de réponse de rétention aux apports d'azote les plus proches du besoin pour un dépôt azoté maximum, permettant de conserver un rendement élevé d'utilisation des protéines ingérées, ne semble pouvoir se faire sans diminution du rapport entre protéines et énergie c'est-à-dire sans une augmentation de la proportion d'énergie non protéique dans la ration (Campbell et al 1984) (figure 4). En même temps, on constate que la loi de réponse de la rétention azotée à l'énergie devient curvi- 
Tableau 8. Apports en acides aminés digestibles vrais recommandés par unité d'énergie nette ( $g / M c a l)$ pour obtenir la vitesse de croissance maximum des porcs.

\begin{tabular}{|c|c|c|c|c|c|}
\hline \multirow[t]{2}{*}{ Poids } & \multirow{2}{*}{$\begin{array}{c}5-10 \mathrm{~kg} \\
1^{\mathrm{er}} \text { âge }\end{array}$} & \multirow{2}{*}{$\begin{array}{l}10-25 \mathrm{~kg} \\
2^{\text {ime }} \text { âge }\end{array}$} & \multirow{2}{*}{$\begin{array}{c}20-55 \mathrm{~kg} \\
\text { femelles } \\
\text { et mâles } \\
\text { castrés }\end{array}$} & \multicolumn{2}{|c|}{$55-100 \mathrm{~kg}$} \\
\hline & & & & $\begin{array}{c}\text { femelles } \\
\text { et mâles } \\
\text { castrés } \\
\text { restreints }\end{array}$ & $\begin{array}{c}\text { mâles } \\
\text { castrés } \\
\text { à volonté }\end{array}$ \\
\hline Lysine & 5,00 & 4,25 & 3,50 & 3,15 & 2,80 \\
\hline Méthionine & 1,50 & 1,28 & 1,05 & 0,95 & 0,84 \\
\hline Met + Cys & 3,00 & 2,55 & 2,10 & 1,89 & 1,68 \\
\hline Thréonine & 3,25 & 2,76 & 2,28 & 2,05 & 1,82 \\
\hline Tryptophane & 0,90 & 0,77 & 0,63 & 0,57 & 0,50 \\
\hline Isoleucine & 3,00 & 2,55 & 2,10 & 1,89 & 1,68 \\
\hline Leucine & 5,00 & 4,25 & 3,50 & 3,15 & 2,80 \\
\hline Valine & 3,50 & 2,98 & 2,45 & 2,21 & 1,96 \\
\hline Phénylalanine & 2,50 & 2,13 & 1,75 & 1,58 & 1,40 \\
\hline Phe + Tyr & 4,75 & 4,04 & 3,33 & 2,99 & 2,66 \\
\hline Histidine & 1,60 & 1,36 & 1,12 & 1,01 & 0,90 \\
\hline Arginine & 2,10 & 1,79 & 1,47 & 1,32 & 1,18 \\
\hline
\end{tabular}
digestibles sont
établis à partir de celui de la lysine, celui de la lysine,
et désmais exprimés par unité d'énergie nette.
Les apports recommandés en acides aminés

denergie nette.

linéaire alors que la loi de réponse de l'énergie totale fixée, incluant les graisses, reste bien linéaire (Schneider et al 1982). Parallèlement, la part des lipides dans le gain de poids augmente, ce qui permet de garder maximale l'efficacité d'utilisation de l'énergie, et minimale la production de chaleur. Une telle aptitude est par définition limitée chez un animal de type maigre, et ceci explique peut-être en partie la différence d'appétit avec un porc de type gras. Inversement, si l'on désire limiter le dépôt de gras chez des porcs lourds ou conventionnels, on peut pratiquer un rationnement énergétique en imposant un rapport alimentaire protéines:énergie plus élevé que celui suffisant à produire le gain maximum en alimentation à volonté. Cette nécessité de "compenser" la réduction de l'apport d'azote, lorsqu'on pratique une restriction alimentaire des porcs en finition, est connue depuis longtemps (Rérat et al 1971). Elle a été confirmée plus récemment dans le cas de l'acide aminé limitant (lysine) (Batterham et al 1985, Bourdon et Henry 1991).

\section{2 / Recommandations pour le porc en croissance et en finition}

Le principe adopté pour les recommandations consiste à définir d'abord le besoin en lysine, l'acide aminé le plus généralement limitant, puis à appliquer aux autres acides aminés les rapports optimaux à la lysine déterminés lors des différentes approches de la protéine idéale (Henry 1993). Le besoin en lysine exprimé en \% de la ration, puis en g/Mcal d'énergie digestible, a régulièrement augmenté avec l'accroissement du potentiel génétique de croissance musculaire des porcs. Les estimations les plus récentes peuvent être facilement converties en quantité digestible vraie par unité d'énergie nette (tableau 8).

L'estimation du rapport lysine/énergie peut être confrontée à un calcul de type factoriel à partir de la performance attendue et du rende- ment d'utilisation de l'acide aminé. Le besoin en énergie nette dépend bien sûr de la vitesse de croissance et surtout de la teneur en lipides du gain de poids, sa teneur en protéines étant relativement constante (Noblet et al 1994). Mais la vitesse de croissance dépend en grande partie de l'appétit des animaux. Chez des porcs femelles entre 20 et $100 \mathrm{~kg}$ de poids vif, l'appétit maximum (EN) peut être chiffré en multiple de ENe à 2,25. Avec un tel niveau d'ingestion, soit 3,6 Mcal, un porc Large White femelle de souche performante pesant $35 \mathrm{~kg}(\mathrm{ENe}=$ $1,56 \mathrm{Mcal})$ peut croître à $700 \mathrm{~g} / \mathrm{j}$ en déposant $115 \mathrm{~g} / \mathrm{j}$ de protéines et $147 \mathrm{~g} / \mathrm{j}$ de lipides (Noblet et al 1994 et communication personnelle). Le besoin net de lysine pour le dépôt, correspondant au contenu du gain de poids $(8,05 \mathrm{~g})$ à quoi doit s'ajouter la lysine compensant la perte d'entretien $(0,52 \mathrm{~g})$, serait de 8,57 $\mathrm{g} / \mathrm{j}$. L'apport minimal d'une protéine idéale théorique de VB lysine $1,0\left(\mathrm{KN}_{\mathrm{N}}=1,0, \mathrm{CUN}=\right.$ $0,93)$, telle que celle proposée par Fuller et al (1989), serait donc de $2,4 \mathrm{~g} / \mathrm{Mcal}$. De manière plus réaliste, couvert par la protéine idéale de Wang et Fuller (1989), cet apport minimal serait de 2,9 g/Mcal $\left(\mathrm{K}_{\mathrm{Nc}}=0,81, \mathrm{CUN}=0,77\right)$. Or, le CUN estimé avec l' apport de lysine digestible d'un régime maïs-soja considéré comme sub-limitant $(2,8 \mathrm{~g} / \mathrm{Mcal} \mathrm{EN})$ n'est que de 0,70 (d'après Noblet et al 1987). Nous arrivons ainsi à un besoin de $3,4 \mathrm{~g} / \mathrm{Mcal} \mathrm{EN}$ qui serait couvert par les 3,5 g/Mcal recommandés. Toutefois, cette cohérence ne doit pas masquer les incertitudes subsistant sur l'efficacité métabolique de la lysine. En se basant sur les données empiriques disponibles dans la bibliographie, Susenbeth (1993), en accord avec Henry et Dourmad (1993), estime le CUN de la lysine brute à 0,50 duquel on peut déduire pour la lysine digestible (CUDv $=88$ ), chez le même animal, une valeur $\mathrm{K}_{\mathrm{Nc}}$ de 0,614 qui conduirait à un besoin $14 \%$ plus élevé. Il est possible que l'amélioration génétique des animaux, comme l'utilisation de génotypes, voire de types sexuels, plus maigres, se soit accompagnée d'une amélioration de l'efficacité d'utilisa- 
tion des protéines. De plus, des progrès importants, quoique difficiles à évaluer, semblent possibles avec la suppression des excès d'acides aminés essentiels (cf 2.1 et 2.2). En finition, le besoin en $\mathrm{g} / \mathrm{Mcal}$ EN diminue du fait de l'augmentation du dépôt de lipides relativement au dépôt de protéines. Un appétit plus élevé associé à une propension supérieure à déposer des lipides et/ou à un potentiel réduit de dépôt protéique expliquent un besoin plus faible chez les mâles castrés nourris à volonté que chez les femelles. Toutefois, la nécessité de "compenser" la restriction azotée par un apport accru d'acides aminés autorise l'emploi du même aliment pour les femelles nourries à volonté et les mâles castrés restreints .

Pour les autres acides aminés, les valeurs sont déduites des rapports à la lysine recommandés sur la base des études les plus récentes (cf tableau 4). Celles-ci ont généralement confirmé la pertinence des rapports optimaux, établis empiriquement (INRA 1984). On note en particulier des valeurs plus élevées pour les acides aminés soufrés, la thréonine et le tryptophane, c'est-à-dire les acides aminés limitants secondaires, que celles prédites à partir de la composition corporelle. Un apport minimal d'acides aminés soufrés sous forme de méthionine égal à $30 \%$ de l'apport de lysine (Henry et Bourdon 1993), le besoin total étant de $60 \%$, est conforme aux estimations les plus récentes d'une valeur maximum de $54 \%$ (Fuller et al 1989) ou de $50 \%$ (Chung et Baker 1992b) de couverture des besoins par la cystine. Le besoin en thréonine est estimé à $65 \%$ de l'apport de lysine, à un niveau plus bas que les valeurs rapportées par Fuller et al (1989) et Wang et Fuller (1989) en accord avec Wang et Fuller (1990), Chung et Baker (1992a), et Sève et al (1993). Il est à noter que ce rapport est le plus touché par le passage d'une expression en digestible vrai à une expression en digestible apparent. Ainsi, les rapports optimaux thréonine:lysine sont sensiblement équivalents en digestible vrai et en brut $(65 \%)$, alors que la valeur obtenue en digestible apparent ne serait que de $60 \%$. Ceci résulte de la richesse importante des secrétions digestives en thréonine. Rappelons que l'apport exprimé en digestible vrai doit couvrir le besoin de croissance et celui d'entretien y compris la perte digestive endogène non spécifique. Parmi les acides aminés généralement non limitants, la leucine est celui dont le besoin était le plus sous-estimé (INRA 1984, NRC 1988). Toutefois, les valeurs très élevées obtenues pour la leucine et les acides aminés aromatiques par Wang et Fuller (1989) sont probablement excessives (Chung et Baker 1992b). Ceci s'explique par l'interférence de l'adaptation des systèmes enzymatiques de dégradation de ces acides aminés dans la détermination des besoins par la méthode de délétion (Wang et Fuller 1987). Quoi qu'il en soit, les auteurs sont d'accord pour fixer à $50 \%$ la proportion maximale d'apport des acides aminés aromatiques sous forme de tyrosine (Robbins et Baker 1977, Fuller et al 1989). Les estimations des besoins en arginine et en histidine sont basées sur les estimations de Southern et Baker (1983) et de Izquierdo et al (1988).

\section{4 / Equilibres prioritaires entre acides aminés et contraintes additionnelles de formulation}

Ces contraintes résultent des rôles métaboliques et physiologiques particuliers joués par les acides aminés et des interactions répertoriées, sinon définitivement établies, entre eux chez le porc. Certains excès d'acides aminés essentiels doivent être évités pour prévenir des effets néfastes spécifiques sur l'appétit ou le rendement métabolique.

\section{1 / Antagonisme isoleucine et valine/leucine}

On sait que les acides aminés ramifiés sont dégradés par une transaminase musculaire puis une déshydrogénase hépatique mitochondriale communes. Chez le Rat, il est établi que l'excès de leucine stimule de manière excessive l'activité de la déshydrogénase, entraînant un catabolisme accru de valine et surtout d'isoleucine et accroissant ainsi le besoin en ces acides aminés. Chez le porc, malgré une diminution rapide des teneurs plasmatiques en isoleucine et valine lorsqu'on augmente l'excès relatif de leucine, celui-ci doit être très important ( 3 fois l'isoleucine) pour que l'on observe un tel résultat (Henry et al 1976). Toutefois, l'antagonisme est plus facilement observé lorsque l'isoleucine est limitante (Taylor et al 1984), ce qui suggère au moins une modification de son rendement d'utilisation. Par ailleurs, il reste à étudier d'autres interactions éventuelles entre les acides aminés ramifiés, la méthionine et la thréonine, le catabolisme de ces deux derniers acides aminés faisant intervenir le même complexe enzymatique mitochondrial que les acides aminés ramifiés au niveau du foie.

\section{2 / Antagonisme lysine/arginine}

Chez le porc, Buracewski et al (1970) ont mis en évidence un antagonisme entre la lysine et l'arginine au niveau de l'absorption duodénale. En outre, chez le très jeune porcelet, Pharazyn et Bayley (1987) rapportent que l'addition d'arginine libre au régime corrige bien le déficit des protéines de lait, en accord avec Leibholz (1982), mais qu'un excès annule l'effet bénéfique en freinant l'absorption intestinale de la lysine. Toutefois, selon Southern et Baker (1982) et Edmonds et Baker (1987), l'effet dépressif de l'arginine ne s'observerait que pour de larges excès et résulterait plus d'un "imbalance" non spécifique affectant l'appétit que d'un antagonisme avec la lysine.

\section{3 / Antagonisme tryptophane/acides aminés neutres}

La carence en tryptophane est connue pour déprimer gravement la consommation d'aliment chez le porc (Henry et Pastuszewska 1976, Montgomery et al 1980). Cette observation résulterait de la déplétion consécutive du cerveau en sérotonine, celle-ci inhibant la 
Tableau 9. Effets de l'addition de protéines (+prot) ou d'acide glutamique (+glu) à un régime déficient ou adéquat en thréonine (basal) sur les performances zootechniques et les activités de la thréonine déshydrogénase (TDG) et de la thréonine déshydratase hépatiques (TDH) chez des porcs femelles en finition (Le Floc'h et al 1992).

\begin{tabular}{|c|c|c|c|c|c|c|}
\hline $\begin{array}{l}\text { Thréonine }(\%) \\
\text { Régime } \\
\text { Protéines }(\%)\end{array}$ & $\begin{array}{c}\text { Basal } \\
12,9\end{array}$ & $\begin{array}{c}0,42 \\
+ \text { prot } \\
15,6\end{array}$ & $\begin{array}{c}+ \text { glu } \\
14,8\end{array}$ & $\begin{array}{c}\text { Basal } \\
13,0\end{array}$ & $\begin{array}{c}0,52 \\
+ \text { prot } \\
15,5\end{array}$ & $\begin{array}{l}+ \text { glu } \\
14,5\end{array}$ \\
\hline Ingéré (kg/j) & $2,41 \mathrm{a}$ & $2,39 \mathrm{a}$ & $2,61 \mathrm{~b}$ & $2,71 b$ & $2,65 \mathrm{~b}$ & $2,57 \mathrm{~b}$ \\
\hline Gain $(\mathrm{kg} / \mathrm{j})$ & $0,77 \mathrm{a}$ & $0,74 \mathrm{a}$ & $0,90 \mathrm{~b}$ & $1,02 c$ & $1,02 \mathrm{c}$ & $0,98 \mathrm{bc}$ \\
\hline Indice (Ingéré/gain) & $3,19 \mathrm{a}$ & $3,28 \mathrm{a}$ & $2,89 \mathrm{~b}$ & $2,65 \mathrm{c}$ & $2,60 \mathrm{c}$ & $2,62 \mathrm{c}$ \\
\hline TDG (U/kg PV) & $32,8 \mathrm{a}$ & $46,7 \mathrm{ab}$ & $73,5 \mathrm{~cd}$ & $57,1 \mathrm{bc}$ & $87,72 \mathrm{~d}$ & $72,6 \mathrm{~cd}$ \\
\hline TDH (U/kg PV) & $0,77 \mathrm{a}$ & $0,73 \mathrm{a}$ & $1,18 \mathrm{bc}$ & $0,91 \mathrm{ab}$ & $1,18 \mathrm{bc}$ & $1,35 \mathrm{c}$ \\
\hline
\end{tabular}

Les valeurs suivies de lettres différentes sont significativement différentes à $\mathrm{P}<0,10$.

consommation de glucides mais favorisant la consommation de protéines (Fernstrom et Wurtman 1972). Nous avons observé chez le porcelet une relation étroite entre l'apport alimentaire de tryptophane et les teneurs en hydroxy-indoles du cerveau (Meunier-Salaün et al 1991). En réalité, l'inhibition de la synthèse de sérotonine serait due à la compétition entre son précurseur, le tryptophane (TRP), et les autres acides aminés essentiels neutres (AAN = acides aminés aromatiques, tyrosine et phénylalanine plus acides aminés ramifiés, valine, isoleucine et leucine) empruntant le même système de transport pour le franchissement de la barrière hémato-encéphalique, lorsque le rapport plasmatique TRP:AAN est insuffisant (Sève et al 1991, Henry et al 1992).

L'augmentation de la teneur de l'aliment en protéines, et donc en acides aminés neutres, sans modification de la teneur en tryptophane suffit à réduire gravement l'appétit et les performances des porcs, surtout les femelles (Henry et al 1992). En revanche, l'augmentation de l'apport d'acides aminés non indispensables reste sans effet. La diminution de l'ingestion d'aliment est donc directement en relation avec la réduction du rapport TRP/AAN dans l'aliment et dans le plasma, lorsque l'apport de tryptophane est abaissé à taux constant.de protéines, ou lorsque le taux de protéines est augmenté à taux constant de tryptophane. En pratique, avec des régimes mais-soja-corn gluten feed-pois, on confirme que le tryptophane alimentaire ne doit pas respecter seulement un rapport optimum à la lysine $(0,18 \mathrm{~g} / \mathrm{g})$ ou par unité d'énergie $(0,7 \mathrm{~g} / \mathrm{Mcal}$ EN) mais également un rapport minimal à la somme des autres AAN (0,04 g/g) (Henry 1993, Henry et Sève 1993a).

\section{4 / Epargne de thréonine par des acides aminés non essentiels}

Récemment, nous avons montré que l'addition de protéines à un régime carencé en thréonine influence peu l'ingestion et les performances (Le Floc'h et al 1992). L'addition au régime carencé de la même quantité d'azote sous forme d'acide glutamique libre (les protéines en renferment une certaine quantité) entraine au contraire une stimulation de l'appétit et de la croissance, tout comme la supplémentation en thréonine libre nécessaire à la couverture du besoin. Cet effet favorable de l'acide glutamique n'est pas observé lorsqu'il est ajouté à un régime équilibré. Seules les femelles sont concernées, peut-être parce qu'en phase de finition elles sont encore en croissance musculaire intense, à la différence des mâles castrés (tableau 9). Ce résultat signifie soit que l' acide glutamique remplace la thréonine dans un rôle physiologique particulier favorable à la croissance, soit qu'il permet d'en épargner. On constate en même temps, toujours avec le déficit de thréonine, que l'acide glutamique entraîne une multiplication par 2,5 de l'activité thréonine déshydrogénase produisant de la glycine. On peut donc se demander si l'effet observé n'est pas lié au déficit alimentaire de glycine et à la nécessité d'une synthèse de novo de cet acide aminé. A l'appui de cette interprétation, il semble que la supplémentation en acide glutamique et en glycine d'un régime blé-soja-arachide réduise sa déficience en thréonine (Sève et al 1993). Toutefois, des résultats récents infirment cette hypothèse (Le Floc'h et al non publié). En réalité, la compétition entre les acides aminés neutres légers (glycine, alanine, sérine, cystéine, thréonine) pour le système de transport dans le foie et les tissus périphériques joue sans doute un rôle majeur dans l'épargne de thréonine (Le Floc'h et al 1994).

\section{5 / La question de l'excès de thréonine chez le porcelet}

Selon les travaux de l'équipe de Harper, une inhibition de l'appétit serait provoquée par l'arrivée massive dans le cerveau des acides aminés en excès relatif dans la ration (Peng et al 1973). Edmonds et Baker (1987) montrent que le porc s'adapte à de très larges excès d'acides aminés essentiels. Toutefois, certains résultats suggèrent qu'il peut être sensible à des excès marginaux.

On sait que les enzymes dégradant la thréonine ne sont pas induites par leur substrat, mais plutôt par l'ensemble des protéines de la ration (Kang-Lee et Harper 1978). Nous avons 
Figure 5. Effet d'un déficit alimentaire de tryptophane sur l'accumulation de thréonine dans le plasma de porcelets nourris ou à jeun (Sève et al 1991) et conséquence sur l'accumulation de thréonine dans le cerveau (Meunier Salaün et al 1991).

Thréonine plasmatique $(\mathrm{mg} / 100 \mathrm{ml})$

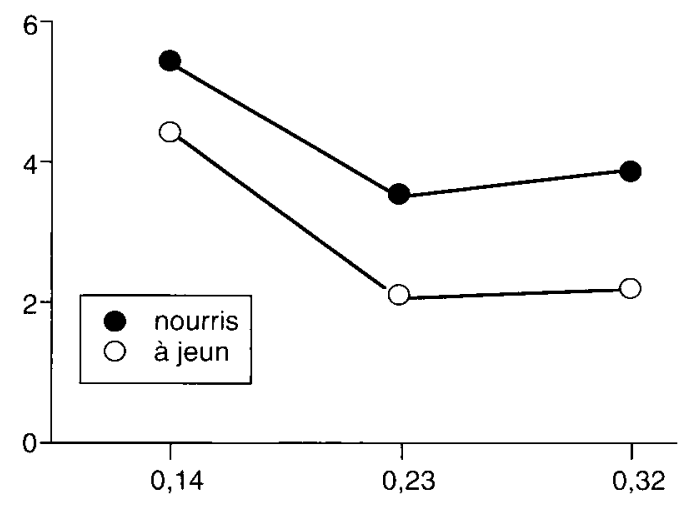

Thréonine $(\mu \mathrm{g} / 100 \mathrm{mg}$ tissu)

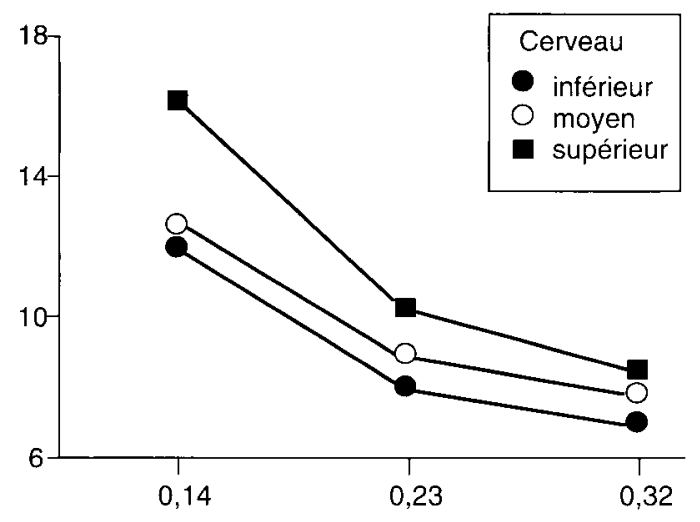

Teneur du régime en tryptophane (\%)

récemment confirmé que c'était bien le cas de la thréonine déshydrogénase (TDG) (Schaeffer et al 1991), principale enzyme de dégradation de la thréonine chez le porc (Ballevre et al 1990). D'ailleurs, le porc semble s'adapter à une carence en protéines, comme à un jeûne prolongé (48 h), par une réduction d'activité de la TDG hépatique (Ballèvre et al 1991). De nombreuses expériences démontrent l'intérêt de corriger un déficit secondaire éventuel des aliments par l'addition de thréonine libre. Aux apports de thréonine excédant le besoin, on observe une accumulation postprandiale de thréonine dans le plasma s'accompagnant parfois d'une réduction d'ingestion d'aliment (Rosell et Zimmerman 1985). Nous avons montré dans des conditions similaires un effet dépressif de l'excès de thréonine sur l'appétit et les performances, peu atténué par la pratique d'une alimentation discontinue (Sève non publié, in Henry et Sève 1993b). Le captage et/ou l'oxydation tissulaire de la thréonine accumulée dans le plasma paraît donc difficile, même si on allonge la période de jeûne interprandial. La même observation est faite chez des porcelets recevant un régime déficitaire en tryptophane, le taux de thréonine du plasma restant élevé même après un jeûne nocturne
Figure 6. Effet à long terme du rapport thréonine/lysine (Thr/Lys) dans un régime de sevrage, distribué pendant 28 jours, sur la vitesse de croissance mesurée du sevrage à différents stades. Les chiffres indiqués sur chaque courbe représentent les niveaux de signification des écarts au point Thr/Lys $=0,52$ (points Thr/Lys = 0,58 et 0,64 ) et au point $T h r / L y s=0,64$ (points Thr/Lys $=0,70$ et 0,76 ) (Sève, non publié).

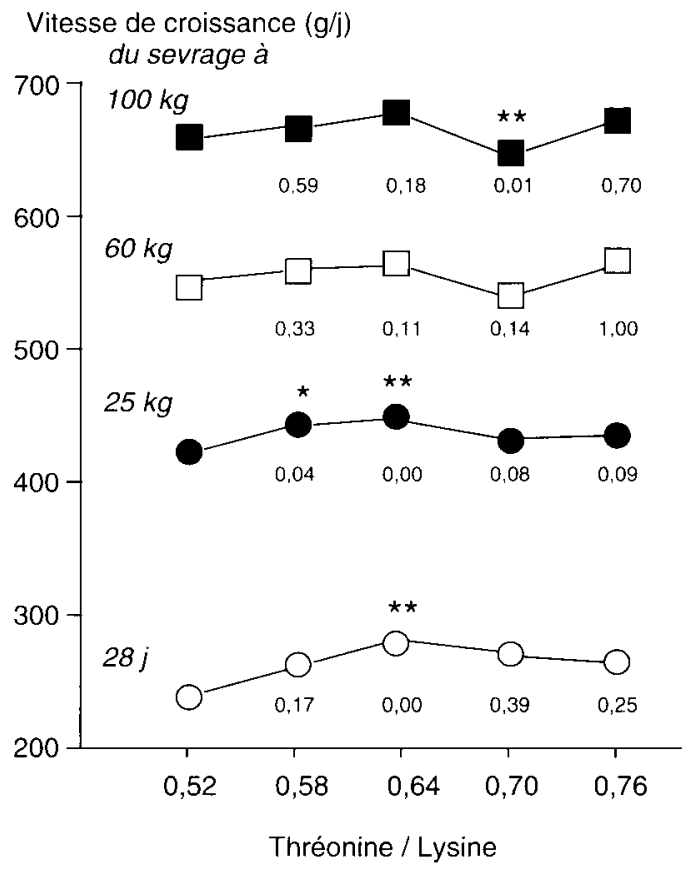

(Sève et al 1991). Dans ce dernier cas, il était clair que la thréonine cérébrale s'élevait simultanément (figure 5) accentuant peut-être encore la chute d'appétit attribuable à la déplétion de sérotonine cérébrale (Meunier-Salaün et al 1991). Il faut être attentif au risque d'excès marginal de thréonine, son effet dépressif sur les performances paraissant, à long terme, plus grave que celui d'une carence (figure 6). Le risque est sans doute atténué lorsque le taux de protéines totales de la ration est suffisamment élevé (Sève non publié, in Henry et Sève 1993b), suite à l'induction de la TDG permettant de limiter l'accumulation plasmatique de thréonine (Schaeffer et al 1991).

\section{Conclusions et perspectives}

Les résultats récents des recherches permettent de formuler des recommandations d'apports minimaux d'acides aminés digestibles (digestibilité iléale vraie) par unité d'énergie nette, constituant un progrès évident comparativement à des recommandations antérieures exprimées en acides aminés bruts par unité d'énergie digestible. En application du concept de protéine idéale, l'identification d'équilibres prioritaires entre les acides aminés permet en outre de limiter les inconvénients de l'apport excessif de certains d'entre eux sur l'appétit ou sur le rendement d'utilisation du facteur limitant. Toutefois, des difficul- 
tés subsistent dans l'estimation de la disponibilité digestive des acides aminés. Des équations de prédiction de la digestibilité iléale doivent encore être établies et validées pour chaque type de protéine. De plus, la signification de la fraction indigestible d'origine endogène spécifique de la matière première devra être établie. Il s'agit, au niveau de l'appareil digestif, de la particularisation d'un problème plus général, celui du rendement métabolique d'utilisation des acides aminés. A cet égard, les travaux doivent se focaliser maintenant sur la marge de progrès, apparemment importante, de ce rendement et, plus particulièrement, sur l'analyse des effets respectifs des excès d'acides aminés essentiels et de l'apport d'acides aminés non essentiels dans le métabolisme.

Par ailleurs, on sait que la recherche de la vitesse de croissance maximum ne répond pas à l'exigence d'optimiser le niveau des performances en fonction des impératifs économiques ou écologiques de valorisation de l'aliment, ou l'utilisation des génotypes disponibles pour la production de viande maigre, dans le respect de l'environnement. L'approfondissement de la connaissance des lois de réponse des performances aux nutriments et la mise au point de modèles de prédiction de la croissance constituent donc une autre priorité.

\section{Références bibliographiques}

ARC, 1981. The Nutrient Requirements of Pigs. 307 pp. C.A.B., Farnham Royal, Slough, England.

Ballèvre O., Cadenhead A., Calder A.G., Rees W.D., Lobley G.E., Fuller M.F., Garlick P.J., 1990. Quantitative partition of threonine oxidation in pigs : effect of dietary threonine. Am. J. of Physiol., 259 (Endocrinol. Metab., 22), E483 - E491.

Ballèvre O., Houlier M.L., Prugnaud J., Bayle G. Bercovici, D., Sève B., Arnal M., 1991. Altered partition of threonine metabolism in pigs by proteinfree feeding or starvation. Am. J. Physiol., 261 (Endocrinol. Metab., 24), E748-E757.

Batterham E. S., 1984. Utilization of free lysine by pigs. Pigs News Information, 5, 85-89.

Batterham E. S., 1992. Availability and utilization of amino acids for growing pigs. Nutr. Res. Rev., 5, 1-18.

Batterham E. S., Bayley H. S., 1989. Effect of frequency of feeding diets containing free or proteinbound lysine on the oxidation of $[14 \mathrm{C}]$ lysine or [14C]phenylalanine by growing pigs. Br. J. Nutr., 62, 647-655.

Batterham E. S., Giles L. R., Dettmann B. E., 1985. Amino acids and energy interactions in growing pigs 2. Effects of food intake, sex and live weight on responses to lysine concentration in barley based diets. Anim. Prod., 42, 133-144.

Bourdon D., Henry Y., 1985. Effets de la supplémentation en lysine industrielle sur les performances de croissance chez le porc: Comparaison de deux formes d'apport (HCl et sulfate). Journées Rech. Porcine en France, 17, 371-382.

Bourdon D., Henry Y., 1991. Réponse du porc en finition à la supplémentation du régime en lysine, en fonction du niveau de rationnement et selon le sexe. Journées Rech. Porcine en France, 23, 111-118.

Buracewski S., Chamberlain A. G., Horszczaruk F., Zebrowska T., 1970. Lysine and arginine interactions affecting their absorption from the duodenum in pigs. Proc. Nutr. Soc., 29, 51A.
Campbell R. G., Taverner M. R., Curic D. M., 1984. The influence of the feeding level and dietary protein content onthe growth, body composition and rate of protein deposition in pigs growing from 45 to $90 \mathrm{~kg}$. Anim. Prod., 38, 233-240.

Campbell R. G., Taverner M. R., Curic D. M., 1985a. The influence of feeding level on protein requirement of pigs between 20 and $45 \mathrm{~kg}$ live weight. Anim. Prod., 40, 489-496.

Campbell R. G., Taverner M. R., Curic D. M., 1985b. Effects of sex and energy intake between 48 and $90 \mathrm{~kg}$ live weight on protein deposition in growing pigs. Anim. Prod., 40, 497-503.

Carpenter K. J., 1960. The estimation of available lysine in animal-protein foods. Biochem. J., 77, 604610 .

Carpenter K. J., Booth V. H., 1973. Damage to lysine in food processing: its measurement and its significance. Nutr. Abs. Rev., 43, 423-451.

Chung T. K., Baker D. H., 1991. A chemically defined diet for maximal growth of pigs. J. Nutr., $121,979-984$.

Chung T. K., Baker D. H., 1992a. Ideal amino acid pattern for 10-kilogram pigs. J. Anim. Sci., 70, 31023111.

Chung T. K., Baker D. H., 1992b. Maximal portion of the young pig's sulfur amino acid requirement that can be furnished by cystine. J. Anim. Sci., 70, 11821187.

de Lange C. F. M., Souffrant W. B., Sauer W. C., 1990. Real ileal protein and amino acids digestibilities in feedstuffs for growing pigs as determined with the $15 \mathrm{~N}$-isotope dilution technique. J. Anim. Sci., 68, 409-418.

Dunkin A. C., Black J. L., James J. L., 1986. Nitrogen balance in relation to energy intake in entire male pigs weighing $75 \mathrm{~kg}$. Br. J. Nutr., 55, 201-207. 
Duvaux, C., Guilloteau P., Toullec, R., Sissons, J. W. (1990) A new method of estimating the proportions of different proteins in a mixture using amino acid profiles: application to undigested proteins in the preruminant calf. Ann. Zootech., 39, 9-18.

Edmonds M. S., Baker D. H., 1987. Amino acid excesses for young pigs : effects of excess methionine, tryptophan, threonine or leucine. J. Anim. Sci., $64,1664-1671$.

Erbersdobler H. F., Lee K. H., 1991. Protein digestibility and lysine bioavailability in native and heat treated casein using the homoarginine method in rats. In Proc. 6th Int. Symp. on Protein Metabolism and Nutrition (B. O. Eggum, C. Borsting, A. Danfaer, T. Huelplund, Ed.), pp 30-32, National Institute for Animal Science, Foulum, Denmark.

Fernstrom J. D., Wurtman R. J., 1972. Brain serotonin content : physiological regulation by plasma neutral amino acids. Science, 178, 414-416.

Fuller M. F., McWilliam R., Wang T. C., Giles L. R., 1989. The optimum dietary amino acid pattern for growing pigs. 2. Requirements for maintenance and tissue protein accretion. Br. J. Nutr., 62, 255-267.

Fuller M. F., Garthwaite P., 1993. The form of response of body accretion to dietary amino acid supply. J. Nutr. 123, 957-963.

Furuya S., Kaji Y., 1991. Additivity of the apparent and true digestible amino acid supply in barley, maize, wheat or soya bean based diets for growing pigs. Anim. Feed Sci. Technol., 32, 321-331.

Green S., Bertrand S.L., Duron M.J.C., Maillard R.A., 1987. Digestibility of amino acids in maize, wheat and barley meal, measured en pigs with ileo-rectal anastomosis and isolation of the large intestine. J. Sci. Food Agric., 41, 29-43.

Hagemeister H., Roos N., 1991. Comparison of protein digestibility measured by $15 \mathrm{~N}$ and a homoarginine. In Proc. 6th Int. Symp. on Protein Metabolism and Nutrition (B. O. Eggum, C. Borsting, A. Danfaer, T. Huelplund, Ed.), pp. 36-38, National Institute for Animal Science, Foulum, Denmark.

Heger J., Frydrych Z., Fronek P., 1987. The effect of nonessential nitrogen on the utilization of dietary protein in the growing rat. J. Anim. Physiol. Anim. Nutr., 57, 130-139.

Henry Y., 1993. Affinement du concept de la protéine idéale chez le porc en croissance. INRA Prod. Anim., 6, 199-212.

Henry Y., Bourdon D. 1993. Réduction des intrants azotés dans l'alimentation du porc en croissance: utilisation du modèle de régime à base de blé avec supplémentation en lysine, thréonine et méthionine. Journées Rech. Porcine en France, 25, 263-272.

Henry Y., Dourmad J. Y., 1993. Feeding strategy for minimizing nitrogen output in pigs. In Nitrogen flow in pig production and environmental consequences (M.W.A.Verstegen, L.A.den Hartog, G.J.M.van Kempen and J.H.M.Metz, Ed.), pp 137-150, EAAP Pub.No.69, Pudoc, Wageningen.

Henry Y., Duée P. H., Rérat A., 1976. Isoleucine requirement of the growing pig and leucineisoleucine interrelationship. J. Anim. Sci., 42, 357364.
Henry Y., Pastuszewska B, 1976. Conséquences d'une déficience en tryptophane du régime sur le niveau d'ingestion et les performances du porc. Ann. Zootech., 25, 143-148.

Henry Y., Sève B., 1993a. Prise en compte de l'excès alimentaire d'acides aminés neutres pour la correction de l'équilibre du tryptophane par rapport à la lysine chez le porc en croissance. Journées Rech. Porcine en France, 25, 247-253.

Henry Y., Sève B, 1993b. Feed intake and dietary amino acid balance in growing pigs with special reference to lysine, tryptophan and threonine. Pig News and Information, 13 (1), $35 \mathrm{~N}-43 \mathrm{~N}$.

Henry Y., Sève B., Colléaux Y., Ganier P., Saligaut C., Jégo P., 1992. Interactive effects of dietary levels of tryptophan and protein on voluntary feed intake and growth performance in pigs, in relation to plasma free amino acids and hypothalamic serotonin. J. Anim. Sci., 70, 1873-1887.

Huisman J., Heinz TH., Van Der Poel A. F. B., Van Leeuwen P., Souffrant W. B., Verstegen M. W. A. 1992. True protein digestibility and amounts of endogenous protein measured with the $15 \mathrm{~N}$-dilution technique in piglets fed on peas (Pisum Sativum) and common beans (Phaseolus Vulgaris). Br. J. Nutr., 68, 101-110.

INRA, 1984. L'alimentation des monogastriques : porc, lapin, volailles, $282 \mathrm{pp}$, INRA, Paris.

INRA, 1989. L'alimentation des monogastriques : porc, lapin, volailles, $2^{\text {eme }}$ édition, $282 \mathrm{pp}$, INRA, Paris.

ITCF-Eurolysine 1993. Digestibilité iléale des acides aminés des matières premières chez le porc, ITCF Paris.

Izquierdo O. A., Wedekind K. J., Baker D. H., 1988. Histidine requirement of the young pig. J. Anim. Sci., 66, 2886-2892.

Jondreville C., Van den Broecke J., Delpech A., Gatel F., Bertin J. M., Beaux M. F., Grosjean F. 1994. Facteurs de variation de la digestibilité iléale des acides aminés des céréales chez le porc charcutier. Journées Rech. Porcine en France, 26, 251-258.

Kang-Lee Y. A. E., Harper A. E., 1978. Threonine metabolism in vivo: effect of threonine intake and prior induction of threonine dehydratase in rats. J. Nutr., 108, 163-175

Laplace J.P., Darcy-Vrillon B., Picard M., 1985. Evaluation de la disponibilité des acides aminés: choix raisonné d'une méthode. Journées Rech. Porcine en France, 17, 353-370.

Laplace J. P., Darcy-Vrillon B., Perez J. M., Henry Y., Giger S., Sauvant D., 1989. Associative effects between two fibre sources on ileal and overall digestibilities of amino acids, energy and cell-wall components in growing pigs. Br. J. Nutr., 61, 75-87

Le Floc'h N., Sève B., Henry Y., 1992. Threonine dehydrogenase in growing pigs fed threonine deficient diets : effect of glutamic acid or protein addition. Proc. Nutr. Soc., 51, 171A.

Le Floc'h N., Sève B., Henry Y., 1994. The addition of glutamic acid or protein to a threonine-deficient diet differencially affects growth performance and threonine dehydrogenase activity in fattening pigs. J. Nutr., sous presse. 
Le Guen M. P. 1993. Pea protein for piglets : effects on digestive processes. Thèse, $150 \mathrm{pp}$, Wageningen.

Leibholz J., 1982. Arginine requirements of pigs between 7 and 28 days of age. Aust. J. Agric. Res., $33,165-170$.

Mariscal-Landin G., 1992. Facteurs de variation de l'utilisation digestive des acides aminés chez le porc. Thèse, 134 pp, Université Rennes 1.

Mariscal-Landin G., Lebreton Y., Sève B., 1990. Mesure, chez le porc, de l'excrétion d'acides aminés d'origine endogène, au niveau iléal, selon deux méthodes. Journées Rech. Porcines en France, 22, 215-222.

Mariscal-Landin G., Sève B., Colléaux Y. Lebreton Y. 1994. Endogenous amino nitrogen, collected from pigs with end-to-end ileorectal anastomosis is affected by the method of estimation and altered by dietary fiber. J. Nutr. sous presse.

Meunier-Salaün M.C., Monnier M., Colléaux Y., Sève B., Henry Y., 1991. Impact of dietary tryptophan and behavioral type on behavior, plasma cortisol and brain metabolites of young pigs. J. Anim. Sci., 69, 3679-3688.

Mitchell H. H., 1924. The nutritive value of proteins. Physiol. Rev., 4,424-478.

Montgomery G. W., Flux D. S., Greenway R. M., 1980. Tryptophan deficiency in pigs: Changes in food intake and plasma levels of glucose, amino acids, insulin and growth hormone. Horm. Metab. Res., 12, 304-309.

Noblet J., Fortune H., Dubois S., Henry Y., 1989. Nouvelles bases d'estimation des teneurs en énergie digestible, métabolisable et nette des aliments pour le porc. INRA, $106 \mathrm{pp}$, Paris.

Noblet J., Henry Y., Dubois S., 1987. Effect of protein and lysine levels in the diet on body gain composition and energy utilization in growing pigs. J. Anim. Sci., 65, 717-726.

Noblet J., Karege C., Dubois S., 1989. Influence of sex and genotype on energy utilization in growing pigs. In Energy Metabolism of Farm Animals (Y. Van der Honing,W.H. Close Ed.), pp 57-60, EAAP publ. n 43, Pudoc, Wageningen.

Noblet J., Shi X. S., Karège C., Dubois S. 1993. Effets du type sexuel, du niveau d'alimentation, du poids vif et du stade physiologique sur l'utilisation digestive de l'énergie et des nutriments chez le porc: interactions avec la composition du régime. Journées Rech. Porcine en France, 25, 165-180.

Noblet J., Shi X. S., Fortune H., Dubois S., Lechevestrier Y., Corniaux C., Sauvant D., Henry Y. 1994. Teneur en énergie nette des aliments chez le porc. Mesure, prédiction et validation aux différents stades de la vie. Journées Rech. Porcine en France, $26,235-250$.

NRC, 1988. Nutrient Requirements of Swine. Ninth revised edition. Nutrient Requirements of Domestic Animals. National Academy Press, 93 pp, Washington D. C..
Peng Y., Gubin J., Harper A. E., Vavich M. G., Kemmerer A. R., 1973. Food intake regulation: Amino acid toxicity and changes in rat brain and plasma amino acids. J. Nutr., 608-617.

Pharazyn A., Bayley H. S., 1987. Influence of arginine addition to diets with either free or proteinbound amino acids in the oxidation of an indicator amino acid. Proc. 5th Symposium on Protein Metabolism and Nutrition, Rostock. Wiss. Z. Wilhelm Piek Univ. Rostock, 36, 67.

Picard M., Bertrand S., Genin F., Maillard M., 1984. Digestibilité des acides aminés: Intérêt de la technique du shunt iléo-rectal chez le porc. Journées Rech. Porcine en France, 16, 355-360.

Rhône-Poulenc Animal Nutrition, 1989. Nutrition Guide. Eléments pour la formulation des régimes en acides aminés digestibles. Première édition, 35 pp, Commentry France.

Rhône-Poulenc Animal Nutrition, 1993. Rhodimet ${ }^{\text {tm }}$ Nutrition Guide. Feed ingredients formulation in digestible amino acids. Second edition, $55 \mathrm{pp}$, Antony France.

Rérat A., 1971. La valeur biologique des protéines: quelques acquisitions récentes. Ann. Zootech., 20, 193-246.

Rérat A., Henry Y., Desmoulin B., 1971. Influence d'une restriction énergétique sur le besoin azoté de croissance du porc femelle. Journées Rech. Porcine en France, 3, 65-72.

Rérat A., Simoes-Nuñes F., Mendy F., Vaissade P., Vaugelade P., 1992. Splanchnic fluxes of amino acids after duodenal infusion of carbohydrate solutions containing free amino acids or oligopeptides in the non-anesthetized pig. Br. J. Nutr., 68, 111-138.

Roach A.G., Sanderson P., Williams D.R., 1967. Comparison of methods for the determination of available lysine value in animal and vegetable protein source. J. Sci. Fd Agric., 18, 274-278.

Robbins K. R., Baker D. H., 1977. The phenylalanine requirement of the weanling pig and its relationship to dietary tyrosine. J. Anim. Sci., 45, 113-118.

Rosell V. L., Zimmerman D., 1985. Threonine requirement of pigs weighing 5 to $15 \mathrm{~kg}$ and the effect of excess methionine in diets marginal in threonine. J. Anim. Sci., 60, 480-486.

Sato H., Kobayashi T., Jones R. W., Easter R. A., 1987.Tryptophan availability of some feedstuffs determined by pig growth assay. J. Anim. Sci. 64, 191-200.

Schaeffer V., Sève B., Prévoteau H., Dufour-Etienne F., Bercovici D., 1991. Catabolisme hépatique de la Lthréonine chez le porc. Influence du taux protéique de la ration. $27^{\text {rme }}$ Réunion de l'Association Française de Nutrition (abstract)

Schneider W., Gaus G., Michel A., Susenbeth A. Menke K. H., 1982. Effect of level of feeding and body weight on partition of energy in growing pigs. In Energy Metabolism of Farm Animals (A. Ekern and F. Sundstol Ed.), pp 225-228, EAAP publication $\mathrm{n}^{\circ} 29$, Agricultural University, Aas, Norway. 
Sève B., Reeds P. J., Fuller M. F., Cadenhead A Hay S. M., 1986. Protein synthesis and retention in some tissues of the young pig as influenced by dietary protein intake after early weaning. Possible connection to the energy metabolism. Reprod. Nutr. Develop., 26, 849-861.

Sève B., Meunier-Salaün M.C., Monnier M., Colléaux Y., Henry Y., 1991. Impact of dietary tryptophan and behavioral type on growth performance and plasma amino acids of young pigs. J. Anim. Sci., 69, 3689-3698.

Sève B., Ganier P., Henry Y., 1993. Courbe de réponse des performances de croissance à l'apport de thréonine digestible vrai mesuré au niveau iléal chez le porc. Journées Rech. Porcine en France, 25, 255-261.

Sève B., Mariscal-Landin G., Février C., Lechevestrier Y. 1994. Prédiction de la digestibilité iléale des acides aminés chez le porc. Journées Rech. Porcine en France, 26, 259-266.

Southern L. L., Baker D. H., 1982. Performance and concentrations of amino acids in plasma and urine of young pigs fed diets with excesses of either arginine or lysine. J. Anim. Sci., 55, 857-866.

Southern L. L., Baker D. H., 1983. Arginine requirement of the young pig. J. Anim. Sci., 57, 402-412.

Susenbeth A., 1993. A model to describe the effect of nutrition on growth, body composition and nitrogen excretion in pigs. Proc. In Nitrogen flow in pig production and environmental consequences $(M$. W. A. Verstegen, L. A. den Hartog, G.J.M. van Kempen and J.H.M.Metz, Ed.), pp. 90-95, Pudoc, Wageningen.
Taylor S. J., Cole D. J. A., Lewis D., 1984. Amino acid requirements of growing pigs. 5 . The interaction between isoleucine and leucine. Anim. Prod., 38, 257-261.

Van Barneveld R. J., 1993. Effect of heating proteins on the digestibility, availability and utilisation of lysine by growing pigs. Thèse, $221 \mathrm{pp}$, University of Queensland, Australia.

Wang T. C., Fuller M. F., 1987. The adaptation of growing pigs to marginal amino acid deficiencies. Proc. 5th Symposium on Protein Metabolism and Nutrition, Rostock. Wiss. Z. Wilhelm Piek Univ. Rostock, 37, 44-45.

Wang T. C., Fuller M. F., 1989. The optimum dietary amino acid pattern for growing pigs. 1. Experiments by amino acid deletion. Br. J. Nutr., 62, 77-89.

Wang T. C., Fuller M. F., 1990. The effect of the plane of nutrition on the optimum dietary amino acid pattern for pigs. Anim. Prod., 50, 155-164.

Wünsche J., Herrmann U., Meinl M., Hennig U., Kreienbring F., Zwierz P., 1987. Einfluss exogener Faktoren auf die präzäkale Nährstoff- und Aminosäurenresorption, ermittelt an Schweinen mit Ileo-Rektal-Anastomosen. 1. Einfluss des Zerkleinerungsgrades von Getreide. Arch. Anim. Nutr., Berlin, 9, 745-764.

\section{Summary}

Growing pig nutrition : integration of concepts of ideal protein, digestive availability of amino. acids and net energy.

Net energy values of feeds can be calculated from their digestible energy content according to the same equation regardless of the pig physiological status. This involves changes in the hierarchy between feedstuffs, undergrading high protein and high fiber ones and upgrading high starch and high fat ones. Theoretical ideal protein, defined as protein of biological value 1 , is the same concept as net energy for nitrogen supply and requirement. The experimental approach of this protein, through suppression of excess amino acids, suggests large potential improvements in the efficiency of digestible nitrogen utilisation. This efficiency measures the metabolic availability of the limiting amino acid, which is little related to dietary ingredients. Feedstuffs are better qualified by the digestive availability of their amino acids which can be measured by their ileal digestibility. The additivity of digestible amino acid supplies from dietary ingredients suppose a correction of each apparent digestibility value for nonspecific endo- genous losses. The resulting true digestibility values can be predicted from the concentration of specific substances in each feedstuff. However, in the "true" undigestible nitrogen or amino acid content of a feedstuff, the quantity and the amino acid cost of the specific endogenous fraction are unknown. Minimal limiting amino acid supply (lysine) per unit of net energy is always independent of energy intake in pigs less than $55 \mathrm{~kg}$ live weight, while it increases with the level of restriction in heavier barrows. Minimal supplies of other essential amino acids can be worked out from experimental determinations of ideal ratios to lysine. Imbalance by excess of essential amino acids can be prevented by correction (tryptophan/large neutral aminoacids) or limitation (threonine) of their supply in the diet. Furthermore, sparing mechanisms of essential (threonine) by nonessential amino acids could change their optimum ratios to total nitrogen.

SEVE B., 1994. Alimentation du porc en croissance : intégration des concepts de protéine idéale, de disponibilité digestive des acides aminés et d'énergie nette. INRA Prod. Anim., 7 (4), 275-291. 